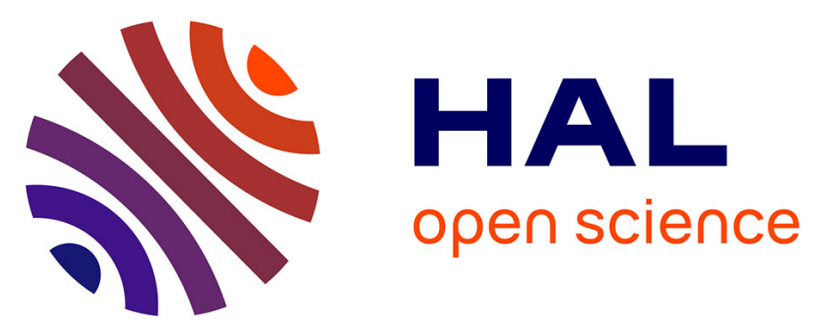

\title{
XAB2 prevents abortive recombinational repair of replication-associated DNA double-strand breaks and its loss is synthetic lethal with RAD52 inhibition
}

Abhishek B Sharma, Hélène Erasimus, Lia Pinto, Marie-Christine Caron, Katrin Neumann, Petr V Nazarov, Barbara Klink, Sabrina Fritah, Christel C Herold-Mende, Simone P Niclou, et al.

\section{To cite this version:}

Abhishek B Sharma, Hélène Erasimus, Lia Pinto, Marie-Christine Caron, Katrin Neumann, et al.. XAB2 prevents abortive recombinational repair of replication-associated DNA double-strand breaks and its loss is synthetic lethal with RAD52 inhibition. 2020. hal-02989098

\section{HAL Id: hal-02989098 \\ https://hal.science/hal-02989098}

Preprint submitted on 5 Nov 2020

HAL is a multi-disciplinary open access archive for the deposit and dissemination of scientific research documents, whether they are published or not. The documents may come from teaching and research institutions in France or abroad, or from public or private research centers.
L'archive ouverte pluridisciplinaire HAL, est destinée au dépôt et à la diffusion de documents scientifiques de niveau recherche, publiés ou non, émanant des établissements d'enseignement et de recherche français ou étrangers, des laboratoires publics ou privés. 
Title

XAB2 prevents abortive recombinational repair of replication-associated DNA doublestrand breaks and its loss is synthetic lethal with RAD52 inhibition

\section{Authors}

Abhishek B. Sharma, ${ }^{1,12}$ Hélène Erasimus, ${ }^{1,2,12}$ Lia Pinto, ${ }^{1,2}$ Marie-Christine Caron, $, 3,4$ Katrin Neumann, ${ }^{1}$ Petr V. Nazarov, ${ }^{5}$ Barbara Klink, $, 6,7$ Sabrina Fritah, ${ }^{8}$ Christel C. HeroldMende, ${ }^{9}$ Simone P. Niclou, ${ }^{8,10}$ Patrick Calsou, ${ }^{11,13}$ Jean-Yves Masson, $, 3,413$ Sébastien Britton, ${ }^{11,13}$ and Eric Van Dyck ${ }^{1,14,}{ }^{*}$

${ }^{1}$ DNA Repair and Chemoresistance Group, Department of Oncology, Luxembourg Institute of Health (LIH), Luxembourg, Luxembourg

${ }^{2}$ Faculty of Science, Technology and Communication, University of Luxembourg, Eschsur-Alzette, Luxembourg

${ }^{3} \mathrm{CHU}$ de Québec Research Center, Oncology Division, Québec City, Canada ${ }^{4}$ Department of Molecular Biology, Medical Biochemistry and Pathology, Laval University Cancer Research Center, Québec City, Canada

${ }^{5}$ Quantitative Biology Unit, Multiomics Data Science Group, LIH, Luxembourg, Luxembourg

${ }^{6}$ National Center of Genetics, Laboratoire National de Santé, Dudelange, Luxembourg ${ }^{7}$ Functional Tumour Genetics Group, Department of Oncology, LIH, Luxembourg ${ }^{8}$ NorLux Neuro-Oncology Laboratory, Department of Oncology, LIH, Luxembourg ${ }^{9}$ Department of Neurosurgery, University Clinic Heidelberg, Heidelberg, Germany ${ }^{10}$ Department of Biomedicine, University of Bergen, Norway

${ }^{11}$ Institut de Pharmacologie et de Biologie Structurale, Université de Toulouse, CNRS, UPS, Toulouse, France, Equipe Labellisée Ligue Nationale Contre le Cancer 2018 ${ }^{12}$ These authors contributed equally 
${ }^{13}$ These authors contributed equally

${ }^{14}$ Lead Contact

*Correspondance: Eric.vandyck@lih.lu

\section{Running title}

XAB2 and RAD52 in single-ended DNA double-strand break repair

\section{Keywords}

DNA double-strand break (DSB) repair; single-ended DNA double-strand break (seDSB); collapsed replication fork; homologous recombination; non-homologous end-joining; DNA end resection; XAB2; RAD52; RAD51; Ku; synthetic lethality; glioblastoma; temozolomide; camptothecin; chemotherapy. 


\section{ABSTRACT}

Unrepaired $\mathrm{O}^{6}$-methylguanine lesions induced by the alkylating chemotherapy agent temozolomide lead to replication-associated single-ended DNA double-strand breaks (seDSBs) that are repaired predominantly through RAD51-mediated homologous recombination $(\mathrm{HR})$. Here, we show that loss of the pre-mRNA splicing and DNA repair protein XAB2 leads to increased temozolomide sensitivity in glioblastoma cells, which reflects abortive $\mathrm{HR}$ due to Ku retention on resected seDSBs. XAB2-dependent Ku eviction also occurred at seDSBs generated by the topoisomerase I poison campthotecin and operated in parallel to an ATM-dependent pathway previously described. Although Ku retention elicited by loss of XAB2 did not prevent RAD51 focus formation, the resulting RAD51-ssDNA associations were unproductive, leading to increased engagement of nonhomologous-end-joining in S/G2 and genetic instability. Overexpression of RAD51 or the single-stranded DNA annealing factor RAD52 rescued the XAB2 defects. RAD52 depletion led to severe temozolomide sensitivity, whereas a synthetic lethality interaction was observed between RAD52 and XAB2. 


\section{Introduction}

Despite surgical resection, ionizing radiation and chemotherapy with the DNA alkylating agent temozolomide (TMZ), glioblastoma (GBM) remains one of the most aggressive and lethal cancers [1, 2], due to chemoresistance driven by complex DNA repair mechanisms. The DNA repair protein $0^{6}$-methylguanine-DNA methyltransferase (MGMT) removes the most cytotoxic lesion induced by $\mathrm{TMZ}, \mathrm{O}^{6}$-methylguanine $\left(\mathrm{O}^{6}-\mathrm{meG}\right)$ [3], providing a major $\mathrm{TMZ}$ resistance mechanism [4]. Epigenetic silencing of MGMT is a predictive and prognostic biomarker in TMZ-treated GBM patients [5]. $\mathrm{O}^{6}-\mathrm{meG}$ lesions left unrepaired by MGMT generate $\mathrm{O}^{6}$-meG/thymidine mismatches during $\mathrm{S}$ phase. These mismatches are recognized, but not resolved, by the mismatch repair (MMR) pathway, resulting in futile repair cycles and persistent single-stranded DNA (ssDNA) gaps that cause replication fork collapse and DNA double-stranded DNA breaks (DSBs) during a subsequent round of replication $[6,7]$.

DSBs resulting from replication fork collapse are single-ended DSBs (seDSBs) [8]. As for two-ended DSBs, seDSBs can be processed by homology-directed or end-joining mechanisms. Homologous recombination (HR) mediated by the RAD51 recombinase plays a central role in replication fork repair in mammalian cells [9] through a pathway called break-induced replication (BIR) [10]. HR is involved in the repair of lesions resulting from $\mathrm{O}^{6}-\mathrm{meG}$ adducts $[11,12]$. During $\mathrm{BIR}$, the seDSB is resected to provide Replication Protein A (RPA)-coated, 3' ssDNA overhangs on which RAD51 operates to replace RPA and assemble nucleoprotein filaments. These filaments mediate homology search and strand invasion into the homologous sister chromatid, generating a displacement loop (Dloop) [13]. The single-strand annealing (SSA) factor RAD52 facilitates the assembly of ssDNA/RAD51 nucleoprotein filaments during HR-mediated seDSB repair in human cells [14]. Similar to yeast RAD52 [13], human RAD52 can also promote BIR mechanisms 
without RAD51. Thus, in cancer cells undergoing replication stress, a BIR pathway has been described which critically depends on RAD52 [15]. RAD52-mediated BIR also promotes mitosis DNA synthesis (MiDAS) at common fragile sites, a process where RAD51 is dispensable [16]. RAD52 forms ring structures that interact with ssDNA, duplex DNA, and DSB ends [17-19]. RAD52 rings expose ssDNA at their outer surface [18, 20, 21] and catalyse the annealing of complementary strands generated during DSB end resection [22-24], as well as second-end capture in the repair of double-ended DSBs [25, 26]. Relevant to BIR, human RAD52 also promotes DNA strand exchange and D-loop formation in vitro [27-29].

Processing of seDSBs by non-homologous end-joining (NHEJ) is a toxic mechanism as it involves the juxtaposition and ligation of distant DNA ends, resulting in chromosomal aberrations and genetic instability [30]. Unlike HR, which is restricted to the S and G2 phases of the cell cycle, NHEJ is active throughout interphase, including G1. In addition, seDSBs termini are initially sequestered by the DNA end-binding heterodimer Ku, a crucial NHEJ factor [31]. Ku binding at seDSBs promotes NHEJ [32] and impairs RAD51-mediated HR [33]. However, fully active HR outcompetes NHEJ in repairing seDSBs in S phase [32].

DNA end resection occurs in the $S$ and $G 2$ phases of the cell cycle and involves the MRE11-RAD50-NBS1 (MRN) complex, C-terminal-binding protein interacting protein (CtIP), exonuclease 1 (EXO1), Bloom syndrome protein (BLM), and DNA2 nuclease/helicase [34]. Resection is initiated at some distance from the seDSB by a nick introduced by the endonuclease activity of MRE11, itself activated by ataxia telangiectasia-mutated (ATM) kinase and CtIP. Bidirectional resection then takes place, mediated by MRE11 exonuclease activity in the 3'-5' direction and EXO1/BLM/DNA2 in the opposite direction, generating ssDNA that recruits RPA. Although the mechanisms leading 
to the subsequent release of Ku remain obscure, for about $40 \%$ of seDSBs induced by the topoisomerase I poison camptothecin (CPT), they involve the coordinated nuclease activities of MRE11 and CtIP, and activation by ATM [33]. Regulation of end resection also involves p53 binding protein 1 (53BP1), effector molecules [34] and the helicase HELB [35]. Recently, several splicing factors have been involved in DNA end resection, including ZNF830 [36], Aquarius [37] and XAB2 [37, 38], by mechanisms that remain to be elucidated.

Targeting DNA repair through inhibition of components of the DNA damage response (DDR) has emerged as an important therapeutic approach against many cancers [39]. As a step to identify novel targets for the sensitization of GBM cells to TMZ, we carried out a shRNA screen for DDR genes that are required for cell proliferation in the presence of TMZ. Here, we report the characterization of XAB2, one of the top hits of this screen, and describe a novel role for XAB2 in promoting Ku eviction and HR at seDSBs.

\section{Results}

XAB2 is involved in the response of GBM cells to temozolomide. As a step to identify novel TMZ sensitizers in GBM cells, we performed a pooled shRNA screen targeting 574 DDR genes for gene depletions that conferred long-term loss of proliferation in the presence of TMZ (but not vehicle) to the GBM cell line NCH644 (Fig. 1a). The screen was carried out in duplicate, using TMZ at a clinically-achievable concentration of $60 \mu \mathrm{M}$ under serum-free conditions and in a monolayer format to ensure uniform TMZ distribution. Cells were harvested following 8 and 15 cumulative population doublings for DNA extraction, library preparation and shRNA read counting via high-throughput sequencing (Fig. 1b). Twenty-six genes were identified as prioritized candidates by overlapping the top ranking genes from 3 analysis algorithms, among which $X A B 2$ (Fig. 1c,d), whose contribution to TMZ-induced DDR was hitherto unexplored. 
We validated $X A B 2$ as a novel TMZ sensitizer using clonogenic assays with $\mathrm{NCH} 644$ cells (GBM cancer stem-like cell line) (Fig. 1e-g) and U87 cells (GBM adherent cell line) (Fig. 1h-j) expressing a control, non-silencing shRNA (shCTRL) or 2 independent shRNAs targeting XAB2.

\section{XAB2 is important for the repair of DSBs associated with $0^{6}$-meG lesions left} unrepaired by MGMT. Given the proposed role of XAB2 in promoting HR [38], we first examined the impact of XAB2 depletion on the repair of DSBs induced by TMZ. We treated control and XAB2-depleted $\mathrm{NCH} 644$ cells with $\mathrm{TMZ}$ for $2 \mathrm{~h}$ and visualized $\gamma \mathrm{H} 2 \mathrm{AX}$ foci, a DSB marker, by indirect immunofluorescence (IF) after a $72 \mathrm{~h}$ recovery period in drug-free medium, corresponding to 2 cell cycles after DNA damage induction.

Compared to control cells, XAB2 depletion led to a $\sim 2$ fold increase in the number of foci observed following exposure to TMZ (Fig. 2a,b), and this accumulation was corroborated by comet assay analysis under neutral conditions, which monitors DSB formation (Fig. 2c,d).

To obtain more insights into the DSB repair defects associated with XAB2 depletion, we characterized adherent U87 GBM cells which are more amenable to IF microscopy. As observed with $\mathrm{NCH} 644$ cells, TMZ exposure led to an increase in $\gamma \mathrm{H} 2 \mathrm{AX}$ foci in control U87-shCTRL cells, displaying maximal foci accumulation at 48 h (i.e. about 2 cell cycles) and a return to background levels at the later time points (Fig. 2e,f). TMZ exposure led to a stronger increase in $\gamma \mathrm{H} 2 \mathrm{AX}$ foci in XAB2-depleted cells compared to control cells. In addition, unlike for control cells, we observed only a moderate decrease in $\gamma \mathrm{H} 2 \mathrm{AX}$ foci at the later time points in XAB2-depleted cells (Fig. 2e,f). Similar observations were made with another DSB marker, 53BP1 (Fig. 2e and 2g). Thus, XAB2 is required for the repair of TMZ-induced DSBs. 
TMZ-induced DSBs can arise when the replication fork collides with ssDNA gaps generated during MMR futile cycling at $\mathrm{O}^{6}$-meG lesions left unrepaired by MGMT. To explore this question, and since U87 cells do not express MGMT, we examined the impact of XAB2 depletion on TMZ-induced $\gamma \mathrm{H} 2 \mathrm{AX}$ and 53BP1 foci formation in otherwise isogenic U87 derivatives ectopically expressing MGMT (Fig. 2h). Stable expression of MGMT prevented the accumulation of $\gamma \mathrm{H} 2 \mathrm{AX}$ and 53BP1 foci associated with XAB2 depletion at all time points (Fig. 2f,g). Similarly, ectopic MGMT overexpression prevented TMZ-induced $\gamma \mathrm{H} 2 \mathrm{AX}$ foci accumulation in XAB2-depleted NCH644 cells (MGMT-positive)

(Supplementary Fig. 1a,b). Taken together, these results indicate that XAB2 promotes the repair of $\mathrm{O}^{6}$-meG-associated seDSBs. To gain support for the notion that XAB2 operates at seDSBs resulting from collapsed replication forks, we examined cells treated with hydroxurea (HU), which depletes the dNTP pool and causes fork stalling (upon short exposure) or collapse (upon long exposure) [40]. As expected, short incubation with HU did not cause significant $\gamma \mathrm{H} 2 \mathrm{AX}$ foci accumulation in control and XAB2-depleted cells whereas prolonged exposure led to a significant increase in $\gamma \mathrm{H} 2 \mathrm{AX}$ and RAD51 recombinase foci accumulation in XAB2-depleted cells compared to control cells (Supplementary Fig. 2a,b).

XAB2-depletion leads to increased engagement of non-homologous end-joining for the repair of seDSBs during $S$ phase. As HR is the preferred repair pathway for seDSBs resulting from collapsed replication forks and RAD51 recombinase acts upon RPA-coated resected seDSBs, we next examined RPA and RAD51 foci formation in TMZ-treated cells. Control and XAB2-depleted cells displayed a similar increase in RPA foci $48 \mathrm{~h}$ after TMZ treatment, indicating efficient end resection (Fig. 3a,b). Moreover, loss of XAB2 led to an increased accumulation of RAD51 foci under these conditions, which paralleled the increase in $\gamma \mathrm{H} 2 \mathrm{AX}$ foci already seen at this time point (Fig. 3a-d). Notably, unlike $\gamma \mathrm{H} 2 \mathrm{AX}$ 
and 53BP1 foci, RAD51 foci did not accumulate significantly at the later time points (Fig. 3c,d). As XAB2 depletion did not affect the percentage of cells in S/G2 and G1 phase at the time points considered, as assessed by Cyclin-A staining (Supplementary Fig. 3), these observations suggest that, in the absence of XAB2, RAD51 did not act on a subset of seDSBs induced by TMZ.

We next tested if NHEJ gained more prominence in XAB2-depleted cells. To this end, we examined foci formation by the Ser1778-phosphorylated form of 53BP1 (pS177853BP1), which has been implicated in NHEJ [41, 42] and the repair of broken replication forks [43]. To relate our findings to cell cycle stages and distinguish cells in S/G2 from G1 cells, we also visualized Cyclin A. In Cyclin A-negative (G1) cells, XAB2 depletion caused an increase in the number of TMZ-induced pS1778-53BP1 foci observed after $72 \mathrm{~h}$ (Fig. $3 e, f)$, consistent with the extra burden of unrepaired damage associated with defective HR. Importantly, under these conditions, XAB2 loss also resulted in a $~ 2.4$ fold increase in pS1778-53BP1 foci in Cyclin A-positive (S/G2) cells (Fig. 3e,f). Furthermore, the percentage of S/G2 cells with more than five pS1778-53BP1 foci reached $~ 87 \%$ in TMZtreated XAB2-depleted cells, compared to $\sim 41 \%$ in control cells (Fig. $3 g$ ). A comparable increase in NHEJ engagement in S/G2 was already observed at $48 \mathrm{~h}$ (Fig. 3g).

One prediction of the increased engagement of NHEJ in the repair of TMZ-induced seDSBs in XAB2-depleted S/G2 cells is that it should be associated with increased genetic instability. Consistent with this notion, loss of XAB2 increased the number of chromosomal aberrations detected in metaphase spreads by 2.5 fold following $T M Z$ exposure (Supplementary Fig. 4a,b).

Loss of XAB2 is associated with $\mathrm{Ku}$ retention on resected DNA repair intermediates and abortive homologous recombination. Although our data indicate that resection and ssDNA/RAD51 associations can occur in the absence of XAB2, the increased 
engagement of NHEJ observed in S phase in XAB2-depleted cells suggests that loss of XAB2 inhibits HR in some way. Based on previous work [33], we considered the possibility that XAB2 depletion led to the Ku persistence at seDSB termini. Following pre-extraction with Triton X-100 and RNAse A to enable IF analysis of $\mathrm{Ku}$ [44], we found that TMZ treatment led to a 1.5 fold increase in Ku80 foci in XAB2-depleted cells compared to control cells (Fig. 4a,b). ATM defines one pathway for Ku release at seDSBs induced by CPT [33]. In agreement with this study, inhibition of ATM kinase activity using the ATM inhibitor (ATMi) KU-55933 [45] also resulted in increased Ku80 foci formation in TMZtreated cells (Fig. 4a). Notably, ATM inhibition further increased the number of Ku80 foci elicited by XAB2 depletion (Fig. 4a). Importantly, Ku80 foci detected following exposure to TMZ were associated with resected seDSBs as assessed by the accumulation of RPA foci. Thus, loss of XAB2 led to a $~ 3$ fold increase in the frequency of Ku80-RPA32 colocalized foci (Fig. 4b-d) compared to control cells. However, contrary to ATM inhibition, which supported end resection whilst preventing RAD51 foci formation in CPT-treated cells [33], XAB2 depletion resulted in a 2.9 fold increase in the frequency of Ku80-RAD51 foci (Fig. 5e-g). Of note, the colocalization data of Fig. $4 c$ and $4 f$ suggest that XAB2 is required to prevent Ku retention at about a third of seDSB termini.

We next sought to extend our findings with U87 cells to seDSBs induced by CPT. Exposure to $1 \mu \mathrm{M} \mathrm{CPT}$ for $1 \mathrm{~h}$ generated equal levels of DNA damage in control and XAB2-depleted cells, as assessed by $\gamma \mathrm{H} 2 \mathrm{AX}$ foci formation (Supplementary Fig. 5a). As seen for TMZ, CPT treatment led to an increase in Ku80 foci in XAB2-depleted cells compared to control cells (Supplementary Fig. 5b,c), which was exacerbated in the presence of ATMi (Supplementary Fig. 5b,c), in agreement with previous work [33]. Furthermore, loss of XAB2 increased the frequency of CPT-induced Ku80-RPA32 colocalized foci ( $>2.5$ fold) and Ku80-RAD51 colocalized foci ( $>1.7$ fold) (Supplementary 
Fig. 5d-f). Finally, whereas the ATM pathway for Ku eviction involves phosphorylation of CtIP [33], we did not observe significant differences in the levels of TMZ- or CPT-induced hyper-phosphorylation of ATM and CtIP in XAB2-depleted cells compared with control cells (Supplementary Fig. 6a-c). We also verified that loss of XAB2 did not affect ATM activity, as determined by the phosphorylation of the ATM target KAP1 [46] in cells treated with TMZ (Supplementary Fig. 5a). Taken together, our data suggest that ATM and XAB2 identify separate pathways for Ku eviction from seDSB termini, with different impacts on RAD51 filament assembly.

In a previous study investigating the role of XAB2 in HR in the U2OS human osteosarcoma cell line, siRNA-mediated depletion of XAB2 resulted in a decrease in CPTinduced chromatin-bound RPA, as assessed by flow cytometry analysis, which was interpreted as indicative of defective end resection [38]. However, similar to U87 cells, we found that shRNA-mediated XAB2 depletion in U2OS cells did not prevent RPA32 and RAD51 foci formation following exposure to CPT (Supplementary Fig. 7a-f), suggesting that end resection was not impaired in these cells. Ruling out possible effects linked to the RNAi method used to deplete XAB2, targeting XAB2 with specific siRNAs (Supplementary Fig. 8a) did not impact RPA32 foci formation (Supplementary Fig. 8b,c). To complement our analysis of RPA foci, we monitored DNA end resection in the siRNA-treated cells through IF visualization of bromodeoxyuridine (BrdU)-labelled ssDNA. XAB2 depletion did not decrease the number/intensity of BrdU foci elicited by CPT compared to control cells (Supplementary Fig. 8d-g). Finally, we showed that XAB2 depletion did not affect CtIP and ATM phosphorylation in U2OS cells treated with CPT, as previously seen in U87 (Supplementary Fig. 8h-i). Collectively, our observations suggest that XAB2 is not required for seDSB end resection but prevents Ku retention and abortive HR at seDSBs induced by CPT and TMZ. 


\section{XAB2 is recruited to temozolomide-associated $\gamma \mathrm{H} 2 \mathrm{AX}$ foci and colocalizes with}

RAD51. As XAB2 is composed essentially of 15 tetratricopeptide repeat (TPR) domains [47] and since TPRs function as protein interaction modules and multiprotein complex scaffolds [48], we next wanted to obtain evidence for a direct role of XAB2 in HR-mediated seDSB repair. Using a XAB2-GFPSpark fusion expressed in U87 cells, we observed a predominantly diffuse nuclear signal in untreated cells, with granular structures that may represent splicing speckles [49] (Fig. 5). However, TMZ treatment resulted in the accumulation of XAB2-GFPSpark foci colocalizing with $\gamma \mathrm{H} 2 \mathrm{AX}$ and/or RAD51 foci (Fig. 5). These observations suggest that the impact of XAB2 depletion on Ku retention at seDSBs stems from a direct role for XAB2 at collapsed replication forks.

\section{Rescue of the DNA repair deficiencies in XAB2-depleted cells by overexpression of}

RAD51 and RAD52. Previous studies in yeast have shown that RAD51 and RAD52 overexpression could suppress defective BIR caused e.g., by dysfunctional RPA stabilization of ssDNA [50]. We found that stable ectopic overexpression of RAD51 or RAD52 (Fig. 6a-c) decreased the number of TMZ-induced $\gamma \mathrm{H} 2 \mathrm{AX}$ foci associated with XAB2 depletion to near background levels, with overexpressed RAD52 affording the strongest rescue at the later time points (Fig. 6b,c). In line with this observation, analysis of the $72 \mathrm{~h}$ time points for Cyclin A and pS1778-53BP1 positivity, revealed that overexpression of RAD52, but not RAD51, reduced NHEJ engagement in S/G2 in XAB2depleted cells to near background levels (Fig. 6d).

RAD52 inhibition is synthetically lethal with XAB2 depletion. Although we did not identify RAD52 in our shRNA screen, the significant rescue afforded by its overexpression in XAB2-depleted cells prompted us to explore its importance in the response of GBM cells to TMZ. shRNA-mediated RAD52 depletion in U87 cells led to a strong sensitivity to TMZ (Fig. 7a-c). We next tried to generate cells harbouring the dual depletion of XAB2 and 
RAD52 using RNA interference. In NCH644, no viable double knockdown cells could be obtained (Fig. 7d), suggesting synthetic lethality. In U87, we obtained double knockdown cells, but their clonogenic survival was severely impaired (Fig. 7e,f).

To corroborate these observations, we carried out real-time cell proliferation analyses following RAD52 inhibition with 6-hydroxy-DL-DOPA (L-DOPA) [51]. In wild-type cells, TMZ had little or no impact on proliferation (Fig. 7g), but exposure to L-DOPA alone impaired proliferation and its effect was exacerbated in combination with TMZ (Fig. $7 \mathrm{~g})$, consistent with the impaired clonogenicity of RAD52-depleted cells (Fig. 7b and 7e). As expected, TMZ impaired the proliferation of XAB2-depleted cells. In addition, RAD52 inhibition by L-DOPA abolished the proliferation of XAB2-depleted cells even in the absence of TMZ (Fig. 7b and 7e).

\section{DISCUSSION}

We found that XAB2 defined a novel mechanism to counteract Ku accumulation at seDSBs. Previous studies have shown that an ATM kinase-dependent pathway involving CtIP and MRE11 operates to counteract Ku retention at about $40 \%$ of seDSB termini [33]. The synergistic impact exerted by ATM inhibition and XAB2 depletion on Ku retention suggests that the XAB2-dependent pathway operates in parallel to the ATM pathway. The XAB2-dependent pathway differs from the ATM-dependent one in that loss of XAB2 does not prevent RAD51 loading on resected DNA ends. This observation suggests that under certain instances RPA-RAD51 exchange on ssDNA may not require coupling to Ku removal. However, overexpression of RAD51 rescued the DNA damage defect associated with XAB2 depletion, indicating that the ssDNA-RAD51 associations that take place on Kubound, resected seDSBs in the absence of XAB2 are not sufficient for efficient recombinational repair (Fig. 8). As XAB2 is present at seDSBs, we propose that XAB2 acts 
via a direct mechanism to promote Ku eviction from resected seDSBs. The molecular details of this novel pathway and its interplay with the ATM-dependent pathway in counteracting $\mathrm{Ku}$ accumulation merit further exploration.

RAD52 overexpression afforded robust rescue of the defects associated with XAB2 depletion. RAD52 can exploit microhomologies [52-54] and its transactions with DNA require moderate resection compared to RAD51-mediated filament formation.

Furthermore, RAD52 competes with Ku for binding to DSB free ends generated in the switch region during antibody class-switch DNA recombination [53], suggesting the possibility that, unlike RAD51, it may be able to operate at seDSBs despite the persistence of Ku or that alternatively, it displaces Ku when overexpressed. Future study will be required to test these hypotheses.

RAD52 acts as mediator of ssDNA/RAD51 filaments during seDSB repair by HR in human cells, a role where it can be replaced by BRCA2 [14]. The severe TMZ sensitivity induced by loss of RAD52 and its strong ability to rescue the defective phenotypes associated with XAB2 depletion suggest that RAD52 also exerts a function independently of RAD51, in line with a previous report [15]. Supporting this notion, we found that not all DSBs seen in XAB2-depleted cells are substrates for RAD51. RAD52 mediates MiDAS independently of RAD51 [16]. It is therefore possible that the residual DSBs observed at $72 \mathrm{~h}$ and $96 \mathrm{~h}$ in XAB2-depleted cells exposed to TMZ, which RAD52 overexpression fully suppressed, reflect in part the participation of XAB2 in MiDAS.

RAD52 inactivation induces synthetic lethality in cells harbouring deficiencies in key HR factors [55-58]. Our observation that XAB2 limits the engagement of NHEJ associated with genome instability can explain why XAB2 was identified in RNAi screens for determinants of PARP inhibitor sensitivity $[59,60]$ or genes that promote genome stability 
[61]. Our data suggest that strategies targeting RAD52 may help improve the therapeutic outcome of patients with glioblastoma.

\section{Methods}

Cell lines, cell cultures and treatments. NCH644 cells were kindly provided by Dr Christel Herold-Mende (Department of Neurosurgery, University of Heidelberg) [62]. NCH644 cells were cultured in in Neurobasal medium (Life Technologies, 21103049) supplemented with 1x B-27 (Life Technologies, 12587010) 2 mM L-Glutamine, $20 \mathrm{U} / \mathrm{ml}$ Pen-Strep, 1 U/ml Heparin (Sigma, H3149-25KU), 20 ng/ml bFGF (Miltenyi, 130-093-841) and $20 \mathrm{ng} / \mathrm{ml}$ EGF (Provitro, 1325950500). For the shRNA screen, 2D cultures of NCH644 were carried out in the same medium using laminin-coated plates. U87 and U2OS cells were cultured in Dulbecco's modified Eagle's medium (Westburg, LO BE12-614F), supplemented with 10\% fetal bovine serum (FBS) (Gibco, 10500-064), 50 U/ml Pen-Strep. Cells were routinely subjected to mycoplasma testing using the Mycoplasma PCR ELISA kit (Sigma Aldrich, 11663925910) and tested negative.

Transductants and transfectants were selected using G418 (300 $\mu \mathrm{g} / \mathrm{ml})$ and/or puromycin $(1 \mu \mathrm{g} / \mathrm{ml})$. Stock solutions of Temozolomide (TMZ, $100 \mathrm{mM})$ (Sigma Aldrich) and Camptothecin (CPT, $50 \mathrm{mM}$ ) (Sigma Aldrich) were prepared in DMSO. RAD52 was inhibited using 6-hydroxy-DL-dopa (L-DOPA, Sigma Aldrich) [51].

shRNA screen, RNA interference and plasmids. The shRNA screen was performed as follows: NCH644 cells grown on laminin-coated plated were infected at an $\mathrm{MOI}$ of 0.3 with a $2.6 \mathrm{~K}$ custom lentiviral shRNA library constructed in pGIPZ puro vector and targeting 574 DNA Damage Response (DDR) genes (i.e., 4.5 shRNAs per gene on average, 700-fold representation)(Thermo Fisher Scientific). Cells were exposed to $1 \mu \mathrm{g} / \mathrm{ml}$ puromycin for 96 $\mathrm{h}$ to allow selection of transductants. Following harvesting of a reference sample (PD0), 
cells were split in 2 arms and cultured under vehicle (DMSO) or $60 \mu \mathrm{M}$ TMZ (which corresponds to the IC20 for $\mathrm{NCH} 644$ interpolated from 2D cytotoxic assays and represents a sub-lethal, therapeutically-reachable dose range [63]). Cells were harvested after cumulative population doubling (PD) 8 and 15 for DNA extraction, library preparation and shRNA read counting via sequencing on an Illumina MiSeq platform. The screen was carried out in duplicate. Screen analysis was performed by comparing shRNAs counts between the vehicle (DMSO) and TMZ treatment conditions using MAGeCK-RRA [64], ScreenBEAM [65] and HitSelect [66]. For each PD, we crossed the lists of the top-15\% candidate genes independently identified by the 3 algorithms and kept their intersection. We then considered as prioritized hits a subset of 26 genes consistently appearing in the 3 analyses both at PD8 and PD15 in both replicates.

shRNA-mediated depletion of XAB2 and RAD52 was carried out using pGIPZ (Dharmacon) or pLKO [67] lentiviral vector-based shRNAs. The following pGIPZ-based shRNAs were used: shXAB2-1 (V2LHS_50670; mature antisense:

TTGACAGAGAATTGGTTCC), shXAB2-2 (V3LHS_645634; mature antisense: ACAAACGTAGCTGTATTGG), shRAD52-2 (V3LHS_376617; mature antisense: TCATGATATGAACCATCCT), shRAD52-3 (V2LHS_171209; mature antisense: ATTGCTTGAGGGCAAGGAG). Lentiviral vectors expressing non-silencing shRNAs in pGIPZ (puromycine resistance marker) (RHS4346) or in pLKO (neomycin resistance marker) [68] were used as negative controls.

siRNA-mediated depletion of XAB2 was achieved using SMARTpool siGENOME XAB2 siRNAs (Dharmacon), with siGENOME Non-targeting control siRNA pool I used as a non-silencing siRNA control (Dharmacon). siRNA transfection were carried out using Lipofectamine RNAiMAX transfection reagent, as detailed in [38]. 
Overexpression of MGMT, RAD51 and RAD52: A Myc-tagged MGMT fragment containing 5'-Xbal extremities and 3'-BamHI extremities was generated by PCR amplification and restriction enzyme digestion and cloned into the lentiviral vector pCDHEF1 $\alpha$-MCS-IRES-Neo and pCDH-EF1 $\alpha$-MCS-IRES-Puro (System Biosciences) predigested with the same restriction enzymes. Lentiviral vectors expressing RAD51 and RAD52 under the EF1 $\alpha$ promoter were constructed by subcloning of a Ncol(blunt)-BamHI fragment containing RAD51 from pFB530 [69] or a Ndel(blunt)-BamH1 fragment containing RAD52 from pFB581 [70] (kindly provided by Dr. S.C. West, Cancer Research UK) into the lentiviral vectors pCDH-EF1 $\alpha$-MCS-IRES-Neo and pCDH-EF1 $\alpha$-MCS-IRESPuro (System Biosciences) cut by EcoRI(blunt)-BamHI. All constructs were verified by sequencing.

Plasmid pCMV3-C expressing XAB2-GFPSpark was obtained from Sino Biological. The fusion construct was subcloned into pCDH-EF1 $\alpha$-MCS-IRES-Puro for long-term expression.

Immunofluorescence (IF) analysis. Cells grown on glass coverslips were incubated with $\mathrm{TMZ}$ (or DMSO) for $2 \mathrm{~h}$ at $37^{\circ} \mathrm{C}$, washed once with media and left to recover in drug-free media for the indicated periods. Cells were then fixed with $4 \%$ paraformaldehyde in PBS for $10 \mathrm{~min}$ at room temperature $(\mathrm{RT})$, permeabilized for 10 min with $0.5 \%$ triton $\mathrm{X}-100$ in PBS and incubated for 30 min at RT in PBS with $2 \%$ bovine serum albumin (BSA) to block nonspecific binding. Thereafter the cells were incubated with primary antibodies at $4^{\circ} \mathrm{C}(90$ min or overnight, depending on the antibody), washed 3 times with PBS and then incubated with secondary antibodies for $1 \mathrm{~h}$ at RT. Cells were counterstained with DAPI and visualized using a Zeiss LSM880 confocal microscope.

For the visualization of Ku foci, cells exposed to DNA damaging agents or vehicle were subjected to pre-extraction using cytoskeleton (CSK) buffer containing $0.7 \%$ Triton X- 
100 and $0.3 \mathrm{mg} / \mathrm{ml}$ RNase $\mathrm{A}(\mathrm{CSK}+\mathrm{R})$ as described [44]. Cells were then fixed with 4\% paraformaldehyde in PBS for 15 min at RT, blocked in PBS containing $10 \%$ fetal bovine serum and $1 \%$ BSA and then incubated with the primary antibodies for 90 min at RT in PBS containing $10 \%$ fetal bovine serum and $1 \%$ BSA. Following 3 washes with PBS, cells were incubated with the secondary antibodies for 60 min at RT in PBS containing $10 \%$ fetal bovine serum and 1\% BSA, followed by washes and DAPI counterstaining. The ATMi KU-55933 (Tocris Biosciences) was used as described in experiments with CPT [44]; it was added during the last half of the $48 \mathrm{~h}$ recovery period following exposure to TMZ.

Analysis of DNA end resection using immunofluorescence visualization BrdUlabelled ssDNA was carried out as previously described [71] with small modifications. In brief, cells were pre-incubated in the presence of $10 \mu \mathrm{M}$ BrdU (Sigma) for 24 hours before the treatment with $1 \mu \mathrm{M} \mathrm{CPT}$ for one hour followed by a release of one hour. Cells were subjected to in situ fractionation on ice for 10 min using sequential extraction with two different buffers. Pre-extraction buffer 1 (10 mM PIPES, pH 7.0, 300 mM sucrose, 100 $\mathrm{mM} \mathrm{NaCl}, 3 \mathrm{mM} \mathrm{MgCl} 2,1 \mathrm{mM}$ EGTA and 0.5\% Triton-X100) and followed by pre-extraction buffer 2 (10 mM Tris $\mathrm{pH}$ 7.5, $10 \mathrm{mM} \mathrm{NaCl}, 3 \mathrm{mM} \mathrm{MgCl}$, $1 \%$ Tween20 and $0.5 \%$ sodium deoxycholate). Cells were washed three times with PBS followed by fixation with 4\% paraformaldehyde $(\mathrm{w} / \mathrm{v})$ for $15 \mathrm{~min}$ at room temperature. Cells were then fixed for 5 minutes with methanol at $-20^{\circ} \mathrm{C}$. Cells were washed with PBS, permeabilized in $0.5 \%$ Triton X-100 in PBS for 10 min and incubated with blocking buffer (PBS $+5 \%$ BSA) for one hour. Cells were incubated overnight at $4^{\circ} \mathrm{C}$ with anti-BrdU and anti-PCNA antibodies in blocking buffer. Unbound primary antibody was removed by washing in PBS at room temperature followed by incubation with the secondary antibodies in PBS $+1 \%$ BSA for one hour at room temperature followed by washes and DAPI counterstaining. Coverslips were mounted onto slides with ProLong Gold antifade mountant. BrdU foci 
were visualized on a DMI6000B microscope.

Metaphase spread preparation and analysis. U87 cells (500,000 cell) exposed to TMZ or vehicle as before were allowed to recover for $45 \mathrm{~h}$ before being incubated in the presence of $0.5 \mu \mathrm{g} / \mathrm{ml}$ colcemid for a further $3 \mathrm{~h}$ at $37^{\circ} \mathrm{C}$. Following trypsination and harvesting, cells were then swelled in $5 \mathrm{ml}$ of pre-warmed hypotonic solution $(0.54 \% \mathrm{KCL})$ added dropwise and incubated at $37^{\circ} \mathrm{C}$ for $30 \mathrm{~min}$. Thereafter, $5 \mathrm{ml}$ of freshly made, icecold fixing solution (ethanol:acetic acid $(3: 1, \mathrm{v} / \mathrm{v}))$ were added and the preparations were stored overnight at $4^{\circ} \mathrm{C}$. Metaphase preparations were dropped onto wet slides, air dried and stained with DAPI for microscopic visualization.

Neutral Comet assay. Cell were embedded in $0.6 \%$ low melting agarose (LMA) and layered onto $0.6 \%$ normal agarose pre-coated frosted slides. Slides were then immersed in pre-chilled lysis buffer $(2.5 \mathrm{M} \mathrm{NaCl}, 10 \mathrm{mM}$ Tris-HCl, $100 \mathrm{mM}$ EDTA pH8.0, 0.5\% triton $\mathrm{X}-100,3 \%$ DMSO, pH9.5) for $1.5 \mathrm{~h}$ and then washed twice with pre-chilled distilled water (2x10min) and twice with pre-chilled electrophoresis buffer (300 mM sodium acetate, 100 mM Tris- $\mathrm{HCl}, 1 \%$ DMSO, pH8.3) (2x10 min). Slides were equilibrated in fresh electrophoresis buffer for $1 \mathrm{~h}$ and then subjected to electrophoresis at $25 \mathrm{~V}(0.6 \mathrm{~V} / \mathrm{cm})$ for $1 \mathrm{~h}$ at $4^{\circ} \mathrm{C}$. DNA was stained with DAPI, imaged with Zeiss LSM 510 confocal laser scanning microscope and pictures were quantified using Perceptive Instruments Comet Assay IV.

Protein extracts and western blot analysis. Cells were harvested, washed once with ice-cold PBS and incubated in 1 x RIPA buffer (Millipore, 20-188) supplemented with protease inhibitor cocktail (Roche, 11697498001) and phosphatase inhibitor cocktail (Roche, 04906837001$)$ for $15 \mathrm{~min}$ at $4^{\circ} \mathrm{C}$. Following centrifugation (16.000 g, $15 \mathrm{~min}$ ) at $4^{\circ} \mathrm{C}$, the lysates were stored at $-20^{\circ} \mathrm{C}$. 
Protein extracts were quantified using the BRADFORD-solution (Bio-RAD, 5000006 ) and heated for $5-10 \mathrm{~min}$ at $95^{\circ} \mathrm{C}$ in LDS-sample loading buffer (Life Technologies, NP0008) containing 50 mM dithiothreitol (Amersham Biosciences, ref.171318-02) before being subjected to SDS-PAGE gel electrophoresis (NuPage ${ }^{\mathrm{TM}} 4-12 \%$ Bis- $^{-}$ Tris Gel Invitrogen, NP0322box) and semi-dry transfer to a nitrocellulose membrane (iBlot ${ }^{\circledR} 2$ NC Mini Stacks Invitrogen, IB23002). The membrane was blocked in PBS containing $0.05 \%$ tween-20 (PBST) and $5 \%$ dry milk for $1 \mathrm{~h}$ at RT and incubated overnight with the appropriate primary antibody. Following 3 washes over 10 min with PBST the membrane was then incubated with the appropriate horseradish peroxidase (HRP)conjugated secondary antibody in PBST containing 5\% dry milk for $1-2 \mathrm{~h}$ at RT. Following 3 washes over 10 min with PBST at RT, signals were detected using ImageQuant LAS400 (General Electric) and images were captured using a SuperSignal ${ }^{\mathrm{TM}}$ West Pico Plus Chemiluminescent Substrate (Thermo Scientific) or SuperSignal ${ }^{\mathrm{TM}}$ West Femto Maximum Sensitivity Substrate (Thermo Scientific).

Colony formation assays. Colony formation assays using U87 cells were carried out as follows: 300 cells were seeded onto $10 \mathrm{~cm}$ dishes and treated with $\mathrm{TMZ}$ for $2 \mathrm{~h}$ at $37^{\circ} \mathrm{C}$ in a humidified atmosphere of $5 \% \mathrm{CO}_{2}$. The medium was then replaced and cells were allowed to form colonies over a period of 15 days. Colonies were stained using crystal violet solution (0.1\% Brilliant blue R (Sigma-Aldrich), in PBS) and quantified using ImageJ/FIJI analysis software.

For NCH644 cells, soft agar colony formation assays were carried out as follows: $6 \times 10^{3} \mathrm{NCH} 644$ cells were suspended in $0.3 \%$ low melting agarose (LMA) containing $1 \mathrm{ml}$ Neural Stem Cell media (NSC-media, Gibco) supplemented with TMZ or vehicle, and then seeded on top of pre-coated $1 \mathrm{ml} 0.6 \%$ LMA containing NSC-media in the 6well plate. Cells were incubated for 21 days at $37^{\circ} \mathrm{C}$ with twice-weekly fresh medium supplementation 
$(200 \mu \mathrm{l})$. After 3 weeks the cells plates were stained with crystal violet for imaging with ImageQuant TL and colony quantification.

Cell proliferation assays. NCH644 cells were seeded medium containing TMZ or vehicle $\left(0.6 \times 10^{6}\right.$ cells in $\left.5 \mathrm{ml}\right)$. They were then split every $3-4$ days under subconfluent conditions while remaining under TMZ or DMSO treatment. At each time point, the cumulative population doublings (PD) was calculated as follows:

$$
\mathrm{PD}(\mathrm{t})=P D_{(t-1)}+\frac{\log \left(\frac{N_{(t)}}{N_{(t-1)}}\right)}{\log (2)}
$$

where $\mathrm{N}(\mathrm{t})$ is the number of cells counted at time $(\mathrm{t})$ and $\mathrm{N}(\mathrm{t}-1)$ is the number of cells seeded at the previous time point, (t-1). Cumulative population doublings were plotted against time.

Real-time cell proliferation analyses with U87 cells were carried using a xCELLigence Real-Time Cell Analyis (RTCA) instrument (ACEA Biosciences Inc.) in a 96well format.

Primary and secondary antibodies used for IF. Primary antibodies: XAB2 (abcam, ab129487, dilution 1:1000), RAD51 (Merck, Ab-1, PC130, dilution 1:1000), $\gamma \mathrm{H} 2 \mathrm{AX}$ (Millipore, Cat. No. 05-636, Clone JBW301, dilution 1:1000), 53BP1 (abcam, ab36823, dilution 1:1000), pS1778-53BP1 (Cell signalling, 26755, dilution 1:1000), Phospho RPA32 (S4/S8) (Bethyl Laboratories, A300-245A, dilution 1:1000), Ku80 (abcam, ab80592, dilution1:1000), BrdU (GE healthcare, RPN202, dilution 1:1000), PCNA (Chromotek, 16D10-100, 1:500). Secondary antibodies: Alexa Flour 647 (Invitrogen, A-21235, dilution 1:500), Alexa Flour 555 (Invitrogen, A-21422, dilution 1:500), Alexa Flour 488 (Invitrogen, A-11001, dilution 1:500), Alexa Fluor 568 (Invitrogen, A-11077, dilution 1:500).

Primary and secondary antibodies used for western blotting. Primary antibodies:

RAD51 (Merk, Ab-1, PC130, dilution 1:1000), RAD52 (Thermo Fisher, PA5-65036, dilution 
1:500), XAB2 (abcam, ab129487, dilution 1:1000), CtIP (Active Motif, 61141, dilution 1:500), ATM (abcam, ab32420 (Y170), dilution: 1:1000), P-ATM (abcam, ab81292 (pS1981), dilution 1:50000), P-KAP1 (Bethyl, IHC-00073 (pS824) dilution 1:200). Secondary antibodies: HRP rabbit (Jackson Laboratory, Cat no 111-035-003, dilution 1:50,000), HRP mouse (Amersham/Sigma, Cat no GENA931-1ML, dilution 1:10,000), HRP mouse (Santa Cruz, sc-516102, dilution 1:10,000).

Statistics and reproducibility. All the error bars are the standard error of mean (s.e.m.), unless mentioned otherwise in the legend. All the graphs are derived from two to five independent repeats. According to the number of samples, statistical significance $(P$ values) of the difference between the means was determined by student $t$-test (two-tailed, upaired), one- or two-ways ANOVA. In the case of non-normally distributed datasets, nonparametric statistical tests have been preferred: Mann-Whitney test for comparisons between two samples and Kruskal-Wallis test for multiple comparisons. Statistical significance was always denoted as follow: ns=not significant; ${ }^{*} p<0.05 ;{ }^{* *} p<0.01$; ${ }^{* * *} p<0.001 ;{ }^{* * * *} p<0.0001$. All statistical analysis was perfprmed using GraphPad Prism 8 (GraphPad Software).

\section{Ackowledgements}

This work was supported by Télévie/Fonds National de la Recherche (F.R.S.-

FNRS)/Fonds National de la Recherche du Luxembourg (FNR) (grant 7.4503.11 to H.E. and E.V.D.; grant 7.4633.16 to A.B.S and E.V.D), the Doctoral School for Systems and Molecular Biomedicine, University of Luxembourg (Grant to H.E.), FNR (PRIDE grant to L.P.), and a Canadian Institutes of Health Research Foundation grant (FDN388879 to J.Y.M.). J.-Y.M. is a FRQS chair in genome stability.

\section{AUTHOR CONTRIBUTIONS}


A.B.S., H.E. and E.V.D. conceived the study. A.B.S. performed experiments to characterize the role of XAB2 in seDSB repair; H.E. carried out the shRNA screen; L.P., M.-C.C, and K.N. performed experiments; P.V.N, B.K. and S.F. contributed to the screen and its analysis; P.V.N, A.B.S., H.E., M.-C.C., J.-Y.M. and L.P. carried out statistical data analysis; C.C.H.-M., P.C. and S.B. contributed cell lines for the study; S.P.N. provided material support and contributed to the screen analysis; J.-Y.M. and S.P.N. provided advice and supervision; P.C., J.-Y.M. and S.B. designed experiments and contributed to data analysis and interpretation. E.V.D. designed, performed and supervised the experiments and wrote the manuscript with comments from the authors.

\section{Competing interests}

The authors declare no competing financial interests.

\section{References}

1. Stupp, R., et al., Radiotherapy plus concomitant and adjuvant temozolomide for glioblastoma. N Engl J Med, 2005. 352(10): p. 987-96.

2. Johnson, D.R. and B.P. O'Neill, Glioblastoma survival in the United States before and during the temozolomide era. J Neurooncol, 2012. 107(2): p. 359-64.

3. Erasimus, $\mathrm{H}$., et al., DNA repair mechanisms and their clinical impact in glioblastoma. Mutat Res Rev Mutat Res, 2016. 769: p. 19-35.

4. Kaina, B., et al., MGMT: key node in the battle against genotoxicity, carcinogenicity and apoptosis induced by alkylating agents. DNA Repair (Amst), 2007. 6(8): p. 107999.

5. Hegi, M.E., et al., MGMT gene silencing and benefit from temozolomide in glioblastoma. N Engl J Med, 2005. 352(10): p. 997-1003.

6. Gupta, D., et al., ATR-Chk1 activation mitigates replication stress caused by mismatch repair-dependent processing of DNA damage. Proc Natl Acad Sci U S A, 2018. 115(7): p. 1523-1528.

7. Quiros, S., W.P. Roos, and B. Kaina, Processing of O6-methylguanine into DNA double-strand breaks requires two rounds of replication whereas apoptosis is also induced in subsequent cell cycles. Cell Cycle, 2010. 9(1): p. 168-78.

8. Zeman, M.K. and K.A. Cimprich, Causes and consequences of replication stress. Nat Cell Biol, 2014. 16(1): p. 2-9.

9. Arnaudeau, C., C. Lundin, and T. Helleday, DNA double-strand breaks associated with replication forks are predominantly repaired by homologous recombination 
involving an exchange mechanism in mammalian cells. J Mol Biol, 2001. 307(5): p. 1235-45.

10. Helleday, T., et al., DNA double-strand break repair: from mechanistic understanding to cancer treatment. DNA Repair (Amst), 2007. 6(7): p. 923-35.

11. Rajesh, $\mathrm{P}$., et al., RAD51D protects against $M L H 1$-dependent cytotoxic responses to O(6)-methylguanine. DNA Repair (Amst), 2010. 9(4): p. 458-67.

12. Roos, W.P., et al., Brca2/Xrcc2 dependent HR, but not NHEJ, is required for protection against $\mathrm{O}(6)$-methylguanine triggered apoptosis, DSBs and chromosomal aberrations by a process leading to SCEs. DNA Repair (Amst), 2009. 8(1): p. 72-86.

13. Anand, R.P., S.T. Lovett, and J.E. Haber, Break-induced DNA replication. Cold Spring Harb Perspect Biol, 2013. 5(12): p. a010397.

14. Whelan, D.R., et al., Spatiotemporal dynamics of homologous recombination repair at single collapsed replication forks. Nat Commun, 2018. 9(1): p. 3882.

15. Sotiriou, S.K., et al., Mammalian RAD52 Functions in Break-Induced Replication Repair of Collapsed DNA Replication Forks. Mol Cell, 2016. 64(6): p. 1127-1134.

16. Bhowmick, R., S. Minocherhomji, and I.D. Hickson, RAD52 Facilitates Mitotic DNA Synthesis Following Replication Stress. Mol Cell, 2016. 64(6): p. 1117-1126.

17. Van Dyck, E., et al., Binding of double-strand breaks in DNA by human Rad52 protein. Nature, 1999. 398(6729): p. 728-31.

18. Stasiak, A.Z., et al., The human Rad52 protein exists as a heptameric ring. Curr Biol, 2000. 10(6): p. 337-40.

19. Van Dyck, E., et al., Visualisation of human rad52 protein and its complexes with hRad51 and DNA. J Mol Biol, 1998. 284(4): p. 1027-38.

20. Parsons, C.A., et al., Precise binding of single-stranded DNA termini by human RAD52 protein. EMBO J, 2000. 19(15): p. 4175-81.

21. Singleton, M.R., et al., Structure of the single-strand annealing domain of human RAD52 protein. Proc Natl Acad Sci U S A, 2002. 99(21): p. 13492-7.

22. Van Dyck, E., et al., Visualization of recombination intermediates produced by RAD52-mediated single-strand annealing. EMBO Rep, 2001. 2(10): p. 905-9.

23. Grimme, J.M., et al., Human Rad52 binds and wraps single-stranded DNA and mediates annealing via two hRad52-ssDNA complexes. Nucleic Acids Res, 2010. 38(9): p. 2917-30.

24. Shinohara, A., et al., Rad52 forms ring structures and co-operates with RPA in singlestrand DNA annealing. Genes Cells, 1998. 3(3): p. 145-56.

25. Nimonkar, A.V., R.A. Sica, and S.C. Kowalczykowski, Rad52 promotes second-end DNA capture in double-stranded break repair to form complement-stabilized joint molecules. Proc Natl Acad Sci U S A, 2009. 106(9): p. 3077-82.

26. Mcllwraith, M.J. and S.C. West, DNA repair synthesis facilitates RAD52-mediated second-end capture during DSB repair. Mol Cell, 2008. 29(4): p. 510-6.

27. $\mathrm{Bi}, \mathrm{B}$., et al., Human and yeast Rad52 proteins promote DNA strand exchange. Proc Natl Acad Sci U S A, 2004. 101(26): p. 9568-72. 
28. Kagawa, W., et al., Homologous pairing promoted by the human Rad52 protein. J Biol Chem, 2001. 276(37): p. 35201-8.

29. Kumar, J.K. and R.C. Gupta, Strand exchange activity of human recombination protein Rad52. Proc Natl Acad Sci U S A, 2004. 101(26): p. 9562-7.

30. Chang, H.H.Y., et al., Non-homologous DNA end joining and alternative pathways to double-strand break repair. Nat Rev Mol Cell Biol, 2017. 18(8): p. 495-506.

31. Shibata, A., P. Jeggo, and M. Lobrich, The pendulum of the Ku-Ku clock. DNA Repair (Amst), 2018. 71: p. 164-171.

32. Balmus, G., et al., ATM orchestrates the DNA-damage response to counter toxic nonhomologous end-joining at broken replication forks. Nat Commun, 2019. 10(1): p. 87.

33. Chanut, P., et al., Coordinated nuclease activities counteract Ku at single-ended DNA double-strand breaks. Nat Commun, 2016. 7: p. 12889.

34. Symington, L.S., Mechanism and regulation of DNA end resection in eukaryotes. Crit Rev Biochem Mol Biol, 2016. 51(3): p. 195-212.

35. Tkac, J., et al., HELB Is a Feedback Inhibitor of DNA End Resection. Mol Cell, 2016. 61(3): p. 405-418.

36. Chen, G., et al., ZNF830 mediates cancer chemoresistance through promoting homologous-recombination repair. Nucleic Acids Res, 2018. 46(3): p. 1266-1279.

37. Sakasai, R., et al., Aquarius is required for proper CtIP expression and homologous recombination repair. Sci Rep, 2017. 7(1): p. 13808.

38. Onyango, D.O., et al., Tetratricopeptide repeat factor XAB2 mediates the end resection step of homologous recombination. Nucleic Acids Res, 2016. 44(12): p. 5702-16.

39. Pilie, P.G., et al., State-of-the-art strategies for targeting the DNA damage response in cancer. Nat Rev Clin Oncol, 2019. 16(2): p. 81-104.

40. Petermann, E., et al., Hydroxyurea-stalled replication forks become progressively inactivated and require two different RAD51-mediated pathways for restart and repair. Mol Cell, 2010. 37(4): p. 492-502.

41. Lee, J.H., et al., Ser1778 of 53BP1 Plays a Role in DNA Double-strand Break Repairs. Korean J Physiol Pharmacol, 2009. 13(5): p. 343-8.

42. Kang, Y., et al., Protein phosphatase 5 regulates the function of 53BP1 after neocarzinostatin-induced DNA damage. J Biol Chem, 2009. 284(15): p. 9845-53.

43. Harding, S.M. and R.G. Bristow, Discordance between phosphorylation and recruitment of 53BP1 in response to DNA double-strand breaks. Cell Cycle, 2012. 11(7): p. 1432-44.

44. Britton, S., J. Coates, and S.P. Jackson, A new method for high-resolution imaging of $\mathrm{Ku}$ foci to decipher mechanisms of DNA double-strand break repair. J Cell Biol, 2013. 202(3): p. 579-95.

45. Hickson, I., et al., Identification and characterization of a novel and specific inhibitor of the ataxia-telangiectasia mutated kinase ATM. Cancer Res, 2004. 64(24): p. 91529. 
46. White, D., et al., The ATM substrate KAP1 controls DNA repair in heterochromatin: regulation by HP1 proteins and serine 473/824 phosphorylation. Mol Cancer Res, 2012. 10(3): p. 401-14.

47. Nakatsu, Y., et al., XAB2, a novel tetratricopeptide repeat protein involved in transcription-coupled DNA repair and transcription. J Biol Chem, 2000. 275(45): p. 34931-7.

48. Zeytuni, N. and R. Zarivach, Structural and functional discussion of the tetra-tricopeptide repeat, a protein interaction module. Structure, 2012. 20(3): p. 397-405.

49. Galganski, L., M.O. Urbanek, and W.J. Krzyzosiak, Nuclear speckles: molecular organization, biological function and role in disease. Nucleic Acids Res, 2017. 45(18): p. 10350-10368.

50. Ruff, P., et al., RPA Stabilization of Single-Stranded DNA Is Critical for Break-Induced Replication. Cell Rep, 2016. 17(12): p. 3359-3368.

51. Chandramouly, G., et al., Small-Molecule Disruption of RAD52 Rings as a Mechanism for Precision Medicine in BRCA-Deficient Cancers. Chem Biol, 2015. 22(11): p. 1491-1504.

52. Villarreal, D.D., et al., Microhomology directs diverse DNA break repair pathways and chromosomal translocations. PLoS Genet, 2012. 8(11): p. e1003026.

53. Zan, H., et al., Rad52 competes with Ku70/Ku86 for binding to S-region DSB ends to modulate antibody class-switch DNA recombination. Nat Commun, 2017. 8: p. 14244.

54. Hastings, P.J., G. Ira, and J.R. Lupski, A microhomology-mediated break-induced replication model for the origin of human copy number variation. PLoS Genet, 2009. 5(1): p. e1000327.

55. Feng, Z., et al., Rad52 inactivation is synthetically lethal with BRCA2 deficiency. Proc Natl Acad Sci U S A, 2011. 108(2): p. 686-91.

56. Lok, B.H., et al., RAD52 inactivation is synthetically lethal with deficiencies in BRCA1 and PALB2 in addition to BRCA2 through RAD51-mediated homologous recombination. Oncogene, 2013. 32(30): p. 3552-8.

57. Chun, J., E.S. Buechelmaier, and S.N. Powell, Rad51 paralog complexes BCDX2 and $\mathrm{CX} 3$ act at different stages in the BRCA1-BRCA2-dependent homologous recombination pathway. Mol Cell Biol, 2013. 33(2): p. 387-95.

58. Wang, H., et al., The concerted roles of FANCM and Rad52 in the protection of common fragile sites. Nat Commun, 2018. 9(1): p. 2791.

59. Lord, C.J., et al., $A$ high-throughput RNA interference screen for DNA repair determinants of PARP inhibitor sensitivity. DNA Repair (Amst), 2008. 7(12): p. 20109.

60. Helleday, T., The underlying mechanism for the PARP and BRCA synthetic lethality: clearing up the misunderstandings. Mol Oncol, 2011. 5(4): p. 387-93.

61. Paulsen, R.D., et al., A genome-wide siRNA screen reveals diverse cellular processes and pathways that mediate genome stability. Mol Cell, 2009. 35(2): p. 22839. 


\section{Additional references}

62. Campos, B., et al., Differentiation therapy exerts antitumor effects on stem-like glioma cells. Clin Cancer Res, 2010. 16(10): p. 2715-28.

63. Ostermann, S., et al., Plasma and cerebrospinal fluid population pharmacokinetics of temozolomide in malignant glioma patients. Clin Cancer Res, 2004. 10(11): p. 372836.

64. Li, W., et al., Quality control, modeling, and visualization of CRISPR screens with MAGeCK-VISPR. Genome Biol, 2015. 16: p. 281.

65. Yu, J., J. Silva, and A. Califano, ScreenBEAM: a novel meta-analysis algorithm for functional genomics screens via Bayesian hierarchical modeling. Bioinformatics, 2016. 32(2): p. 260-7.

66. Diaz, A.A., et al., HiTSelect: a comprehensive tool for high-complexity-pooled screen analysis. Nucleic Acids Res, 2015. 43(3): p. e16.

67. Moffat, J., et al., A lentiviral RNAi library for human and mouse genes applied to an arrayed viral high-content screen. Cell, 2006. 124(6): p. 1283-98.

68. Viel, T., et al., Optimizing glioblastoma temozolomide chemotherapy employing lentiviral-based anti-MGMT shRNA technology. Mol Ther, 2013. 21(3): p. 570-9.

69. Benson, F.E., A. Stasiak, and S.C. West, Purification and characterization of the human Rad51 protein, an analogue of E. coli RecA. EMBO J, 1994. 13(23): p. 576471.

70. Benson, F.E., P. Baumann, and S.C. West, Synergistic actions of Rad51 and Rad52 in recombination and DNA repair. Nature, 1998. 391(6665): p. 401-4.

71. Caron, M.C., et al., Poly(ADP-ribose) polymerase-1 antagonizes DNA resection at double-strand breaks. Nat Commun, 2019. 10(1): p. 2954. 


\section{Figure Legends}

Fig. 1 XAB2 promotes resistance to TMZ in GBM cells. a, Outline of the shRNA screen. NCH644 cells were infected with a pool of shRNA lentiviral particles targeting 574 gene components of the DNA damage response. Following puromycin selection and harvesting of a reference sample (PD0), cells were split into 2 arms and exposed to $60 \mu \mathrm{M}$ TMZ or vehicle (DMSO), respectively. Genomic DNA was extracted from the surviving cell populations harvested after 8 and 15 cumulative population doublings (PD). DNA libraries were prepared and sequenced using a MiSeq platform. MOI: multiplicity of infection. b, $\mathrm{NCH} 644$ cell proliferation assessed under TMZ or DMSO, during the 2 experimental screen replicates. Arrows indicate the PD8 and PD15 time points at which cells were harvested. c, Means of the shRNAs fold changes (FC) (TMZ versus DMSO) for each gene of the libray at PD15 compared to PD8. Highlighted are the genes consistently identified as prioritized candidates by overlapping the top ranking genes from 3 analysis algorithms. d, Heatmap showing the relative depletion of each of the 5 shRNAs targeting $X A B 2$ present in the library, in cells treated with TMZ compared to DMSO, at the indicated PD, in the 2 replicates of the screen. $\mathrm{R} 1$ and $\mathrm{R} 2$ : experimental replicate 1 and 2 , respectively. Normalized count values are depicted using a red (high) to blue (low) color key. e-j, XAB2 depletion results in increased sensitivity to TMZ in NCH644 cells (e-g) and U87 cells (h-j). $\mathbf{e}, \mathbf{h}$, representative immunoblots illustrating the efficiency of XAB2 depletion achieved by 2 independent shRNAs (shXAB2-1 and shXAB2-2) as compared to a control, nonsilencing shRNA (shCTL). Actin was used as a loading control. f, i , Clonogenic survival assays. Cells were exposed to the indicated concentrations of TMZ or vehicle (DMSO) for $2 \mathrm{~h}$ and allowed to form colonies before being stained with crystal violet. $\mathbf{g}, \mathbf{j}$, Quantification of the clonogenic assays following cell counting with ImageJ. Data are the average of $n=3$ or more biological replicates. Bars represent mean \pm s.e.m. Significant 
bioRxiv preprint doi: https://doi.org/10.1101/2020.04.10.035410; this version posted April 11, 2020. The copyright holder for this preprint (which was not certified by peer review) is the author/funder. All rights reserved. No reuse allowed without permission.

differences between specified comparisons were assessed by 2-ways ANOVA, and highlighted by stars $\left({ }^{*} \mathrm{P}<0.05 ;{ }^{* *} \mathrm{P}<0.01 ;{ }^{* * *} \mathrm{P}<0.0001\right)$. 


\section{Fig. 2 | XAB2 depletion impairs the repair of DSBs induced by 06-meG left}

unrepaired by MGMT. a-b, Representative immunofluorescence images of $\gamma \mathrm{H} 2 \mathrm{AX}$ foci (red) in NCH644 cells expressing the indicated shRNAs, following a $2 \mathrm{~h}$ exposure to 100 $\mu \mathrm{M} \mathrm{TMZ}$ (or vehicle) and a $72 \mathrm{~h}$ recovery period (a), and related quantification (b). DNA was counterstained with DAPI (blue). c-d, Control and XAB2-depleted NCH644 cells were treated with $100 \mu \mathrm{M} \mathrm{TMZ}$ (or vehicle) for $2 \mathrm{~h}$ and DNA damage was assessed by neutral comet assay after $72 \mathrm{~h}$. Shown are representative images (c), and related quantification of the average mean tail moments (30 cell/sample/experiment $(n=3)(\mathbf{d})$. e, Representative immunofluorescence images used for the quantification of $\gamma \mathrm{H} 2 \mathrm{AX}$ (red) and 53BP1 (green) foci in control and XAB2-depleted U87 cells following exposure to $15 \mu \mathrm{M}$ TMZ (or DMSO) and recovery in drug-free medium for 48,72 and 96 h. f-g, Quantification of the average $\gamma \mathrm{H} 2 \mathrm{AX}$ foci (f) and 53BP1 foci $(\mathbf{g})$ per nucleus in control and XAB2-depleted U87 cells as well as in derivative cells ectopically overexpressing MGMT. $\mathbf{h}$, Immunoblot analysis of MGMT overexpression in U87 cells. Scale bar $=5 \mu \mathrm{m}$. The images are representative of 3 or more independent biological repeats. Bars represent mean \pm s.e.m. Significant differences between specified comparisons were assessed by Kruskal-Wallis test and are highlighted by stars $\left({ }^{*} \mathrm{P}<0.05 ;{ }^{* *} \mathrm{P}<0.01 ;{ }^{* *} \mathrm{P}<0.001 ;{ }^{* * *} \mathrm{P}<0.0001\right)$. 
Fig. 3 | XAB2 depletion leads to the increased engagement of NHEJ in S/G2. a-b, Representative immunofluorescence images of RPA32 foci (red) and 53BP1 foci (green) in control and XAB2-depleted U87 cells exposed to $15 \mu \mathrm{M} \mathrm{TMZ}$ (or DMSO) for $2 \mathrm{~h}$ and allowed to recover in drug-free medium for $48 \mathrm{~h}(\mathbf{a})$, and related quantification of the average number of RPA32 foci per nucleus (b). c-d, Representative immunofluorescence images of RAD51 foci (green) in control and XAB2-depleted cells exposed to $15 \mu \mathrm{M} \mathrm{TMZ}$ (or DMSO) for $2 \mathrm{~h}$ and allowed to recover in drug-free medium for the indicated times (c), and related quantification (d). Also stained in (c) are $\gamma \mathrm{H} 2 \mathrm{AX}$ foci (red). e-f, Representative immunofluorescence images of control and XAB2-depleted U87 cells following exposure to $15 \mu \mathrm{M}$ TMZ (or DMSO) for $2 \mathrm{~h}, 72 \mathrm{~h}$ recovery in drug-free medium and processing for IF analysis of pS1778-53BP1 foci and Cyclin A (e), and related quantification of the average number of pS1778-53BP1 foci per nucleus, in the total cell population, as well as in Cyclin A-negative and -positive cell subpopulations (f). $\mathbf{g}$, Quantification of the percentage of Cyclin A-positive cells with > 5 pS1778-53BP1 foci per nucleus in control and XAB2depleted U87 cells exposed to $15 \mu \mathrm{M}$ TMZ (or DMSO) for $2 \mathrm{~h}$ before being allowed to recover in drug-free medium for the indicated times. Scale bar=5 $\mu \mathrm{m}$. The images are representative of 3 or more independent biological repeats. Bars represent mean \pm s.e.m. Significant differences between specified comparisons were assessed by Mann-Whitney test in $\mathbf{b}$ and $\mathbf{g}$, 2-ways ANOVA in $\mathbf{d}$, Kruskal-Wallis test in $\mathbf{f}$ and are highlighted by stars $\left({ }^{*} \mathrm{P}<0.05 ;{ }^{* *} \mathrm{P}<0.01 ;{ }^{* *} \mathrm{P}<0.001 ;{ }^{* * *} \mathrm{P}<0.0001\right)$. 
Fig. 4 | XAB2 prevents Ku retention on seDSBs induced by temozolomide. a, Quantification of the average number of Ku80 foci detected by immunofluorescence microscopy in control and XAB2-depleted U87 cells exposed to $15 \mu \mathrm{M} T \mathrm{TZ}$ (or DMSO) for $2 \mathrm{~h}$ and allowed to recover for $48 \mathrm{~h}$ in the absence or presence of the ATMi KU-55933. b, Representative immunofluorescence images used for the quantification of the number of colocalizing Ku80 (red)-RPA32 (cyan) foci following exposure of control and XAB2depleted U87 cells to TMZ and recovery for $48 \mathrm{~h}$. Examples of colocalized foci are highlighted by yellow squares, with one representative example (indicated by an arrow) shown in the close up section (scale bar $=0.1 \mu \mathrm{m}) . \mathbf{c}-\mathbf{d}$, Percentage of colocalized Ku80RPA32 foci per cell following exposure to TMZ as in c, quantified based on foci examination in individual cells, as presented in a violin plot (d). $\mathbf{e}-\mathbf{g}$, Same as $\mathbf{b}$-d for the analysis of Ku80 (red) and RAD51 (cyan) foci colocalization. Scale bar $=5 \mu \mathrm{m}$. The images are representative of 3 independent biological repeats. Bars represent mean \pm s.e.m. Significant differences between specified comparisons were assessed by a t-test (unpaired, 2-tails) and are highlighted by stars $\left({ }^{\star} \mathrm{P}<0.05 ;{ }^{* \star} \mathrm{P}<0.01 ;{ }^{\star \star \star} \mathrm{P}<0.001\right.$; $* * * * P<0.0001)$ 
Fig. 5 | Colocalization of XAB2 with DSBs and RAD51 following DNA damage induced by temozolomide. U87 cells expressing XAB2-GFPSpark were exposed to TMZ for $2 \mathrm{~h}$ and allowed to recover for $48 \mathrm{~h}$ in drug free media before fixation and IF for RAD51 (magenta), $\gamma \mathrm{H} 2 \mathrm{AX}$ (red). Scale bar $=5 \mu \mathrm{m}$. White arrows highlight examples of colocalization between XAB2-GFPSpark, gH2AX and RAD51 foci. The images are representative of 3 independent biological repeats. 
Fig. 6 | Defective XAB2 is partially rescued by overexpression of RAD51 and RAD52

a, Immunoblotting analysis of RAD52 (upper panel) and RAD51 (lower panel)

overexpression in control and XAB2-depleted U87 cells. b-c, Representative micrographs of $\gamma \mathrm{H} 2 \mathrm{AX}$ foci (red) detected by immunofluorescence in the indicated cells exposed to 15 $\mu \mathrm{M} \mathrm{TMZ}$ (or DMSO) for $2 \mathrm{~h}$ and allowed to recover in drug-free medium for the indicated times (b) and related quantification in (c). d, Percentage of Cyclin A-positive cells displaying pS1778-53BP1 foci among control and XAB2-depleted cells harboring the indicated constructs, following exposure to $15 \mu \mathrm{M} \mathrm{TMZ}$ (or DMSO) for $2 \mathrm{~h}$ and recovery in drug-free medium for the indicated times. Data are the average of $n=2$ or more biological replicates (30-50 cells/sample/experiment). Scale bar $=5 \mu \mathrm{m}$. The images are representative of 3 independent biological repeats. Bars represent mean \pm s.e.m. Significant differences between specified comparisons were assessed by Kruskal-Wallis test in $\mathbf{c}$ and 2-ways ANOVA in $\mathbf{d}$ and are highlighted by stars $\left({ }^{*} \mathrm{P}<0.05 ;{ }^{*} \mathrm{P}<0.01\right.$; $\left.{ }^{* *} \mathrm{P}<0.001 ;{ }^{* * *} \mathrm{P}<0.0001\right)$ (ns = not significant). 
Fig. 7 | XAB2 shows synthetic lethality with RAD52. a, Immunoblots illustrating the efficiency of RAD52 depletion achieved by 2 independent shRNAs (shRAD52-1 and shRAD52-2) as compared to shCTRL. Actin was used as a loading control. b-c, Clonogenic survival assays carried out with control and RAD52-depleted cells exposed to $15 \mu \mathrm{M}$ TMZ (or DMSO) for $2 \mathrm{~h}$ (b) and related quantification (c). Cell viabilities are expressed as $\%$ relative to that of untreated cells (set at $100 \%$ ). d, Micrographs of control or XAB2-depleted NCH644 cells transduced with either shRAD52 or control (shCTL) shRNAs, taken at day 18 following transduction and selection in puromycin/G418. Control and XAB2-depleted cells, obtained using shRNA constructs expressing the puromycineresistance marker, were transduced with pLKO-based constructs expressing shCTL or shRAD52-2 shRNAs, followed by additional selection with G418. No spheroid growth was observed in the double knockdown cells. e-f, Quantification of the clonogenic survival of U87 cells following single or double knockdown of XAB2 and RAD52 (e) and representative illustration of the plating efficiency of the double knockdown cells compared to control cells (f). See Fig. $1 \mathrm{i}$ and Fig. 7b for illustrations of the single knockdowns. g, xCELLigence real-time cell proliferation analysis with control and XAB2depleted cells exposed to the indicated concentrations of TMZ and/or L-DOPA, or vehicle. Red arrows indicate the time of drug addition. Images shown are the representative of 3 independent experiments. Scale bar $=250 \mu \mathrm{m}$ Data are the average 3 or more biological replicates. Bars represent mean \pm s.e.m. Significant differences between specified comparisons were assessed by one- or two-ways ANOVA and are highlighted by stars $\left({ }^{*} \mathrm{P}<0.05 ;{ }^{* * *} \mathrm{P}<0.001\right)$. 
Fig. 8 | XAB2 promotes Ku eviction from seDSB termini and HR. Proposed model integrating the present findings. XAB2 defines a novel pathway for Ku eviction from a subset of seDSBs resulting from collapsed replication forks. This pathway operates in parallel to an ATM/MRN/CtIP-dependent pathway previously described (ref 33). Whereas the ATM/MRN/CtIP-dependent pathway is critical for RAD51 loading, loss of XAB2 does not prevent interaction between RAD51 and ssDNA generated through end resection. However, the resulting associations are unproductive, leading to increased NHEJ engagement in S/G2. Such defects can be rescued by overexpression of RAD51 or RAD52. 
a

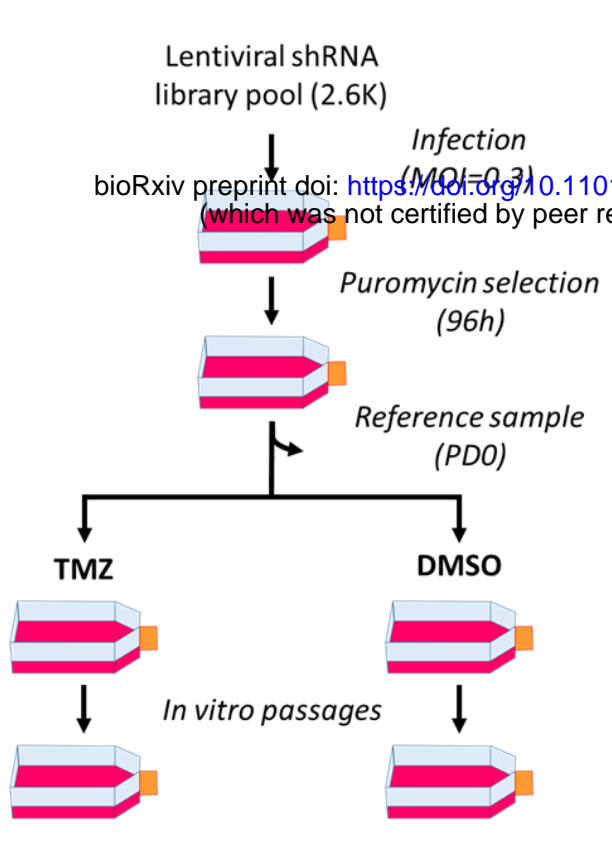

Cell harvesting (PD8 \& PD15), DNA extraction, shRNA amplification and high throughput sequencing b

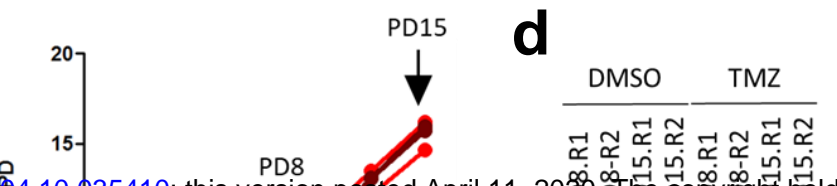

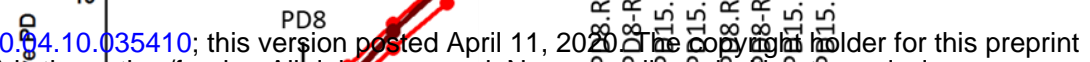
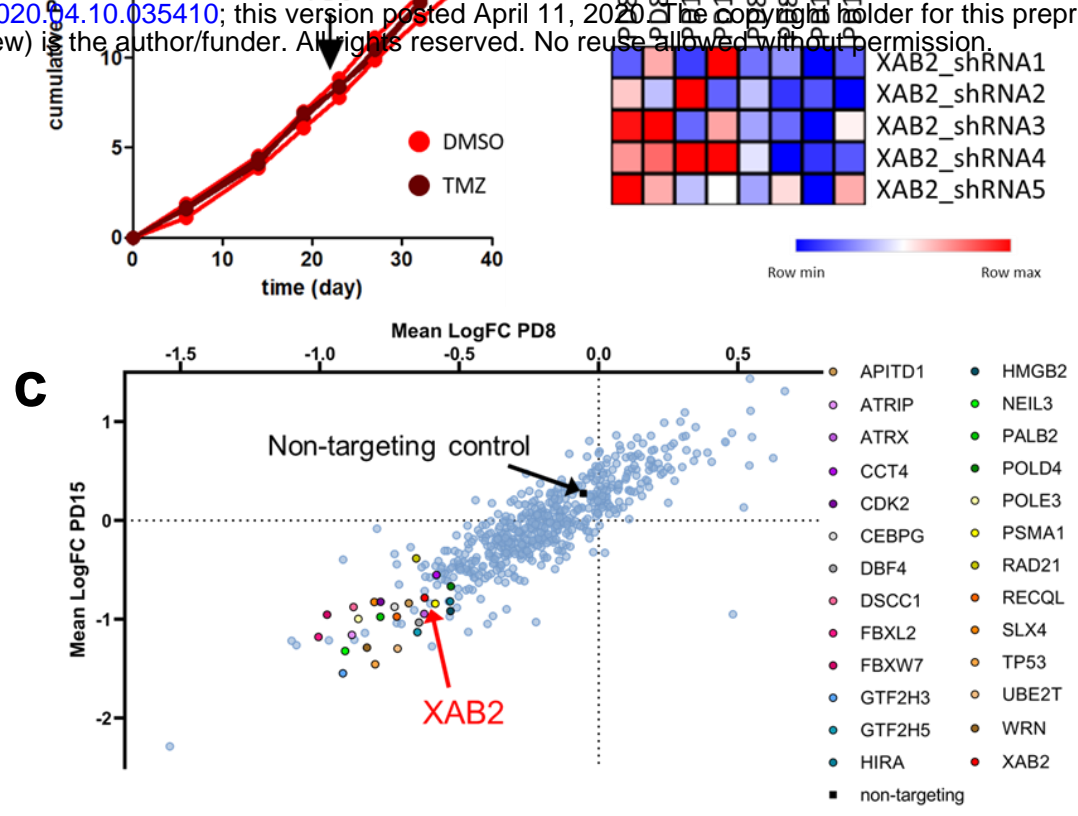

e

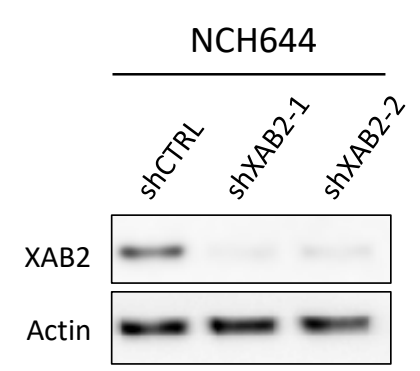

h

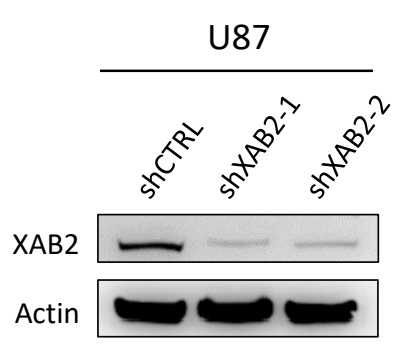

f

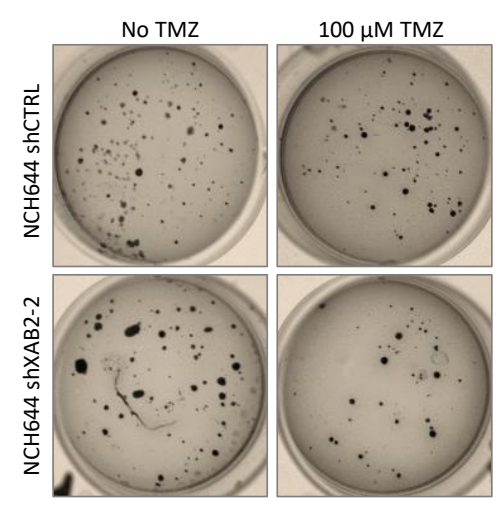

i

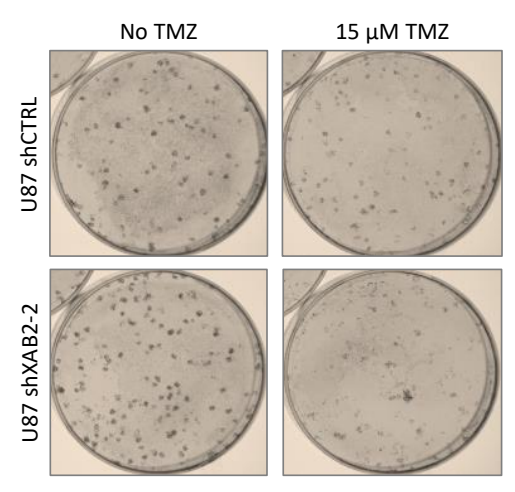

g
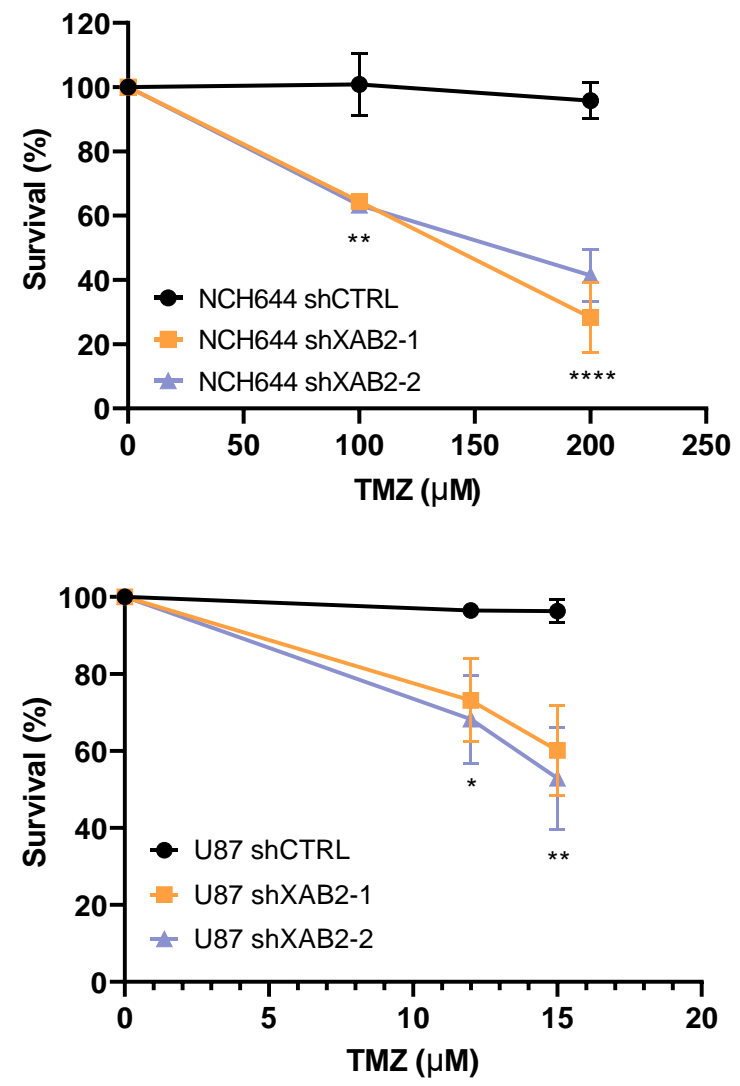


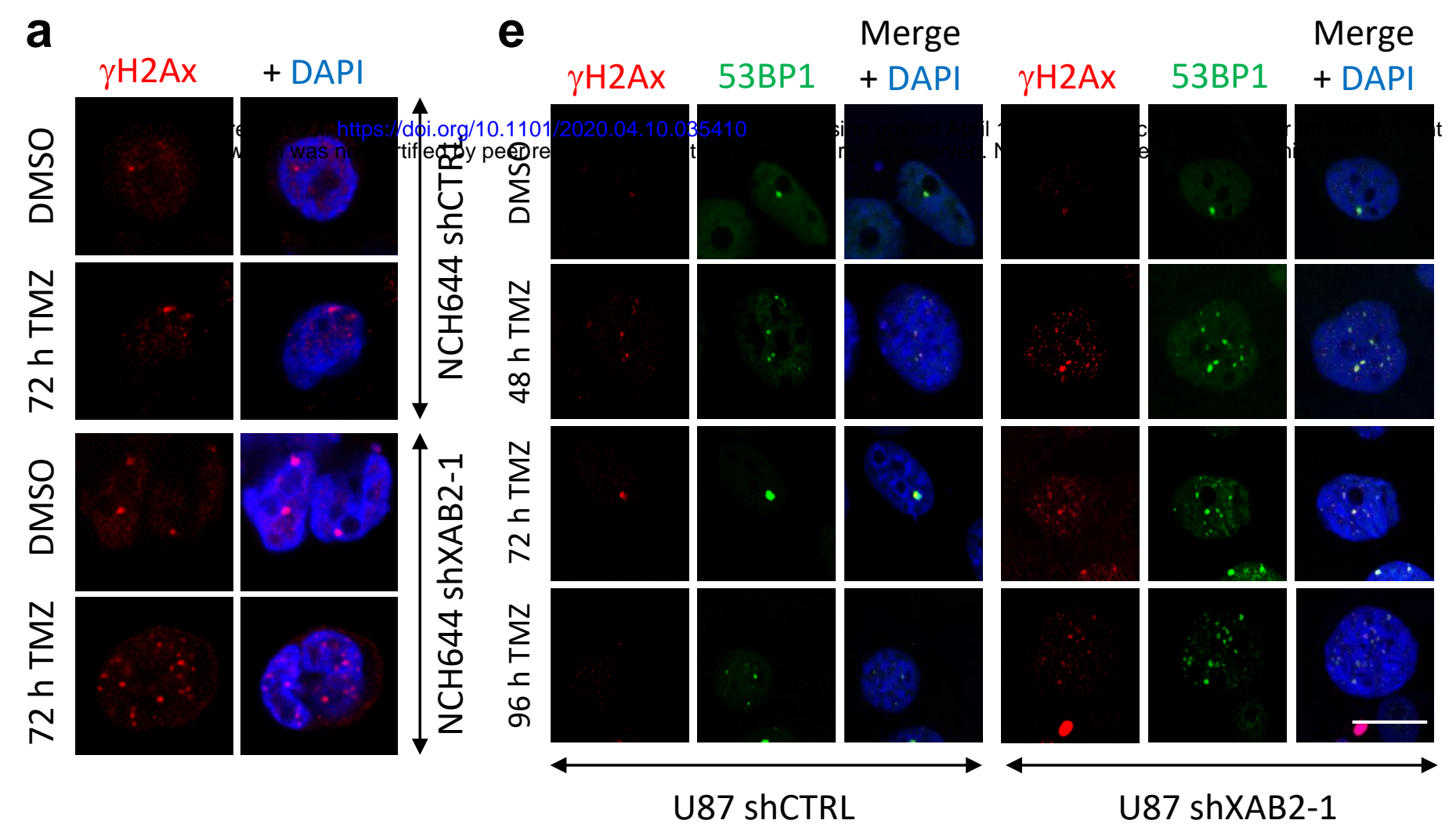

b

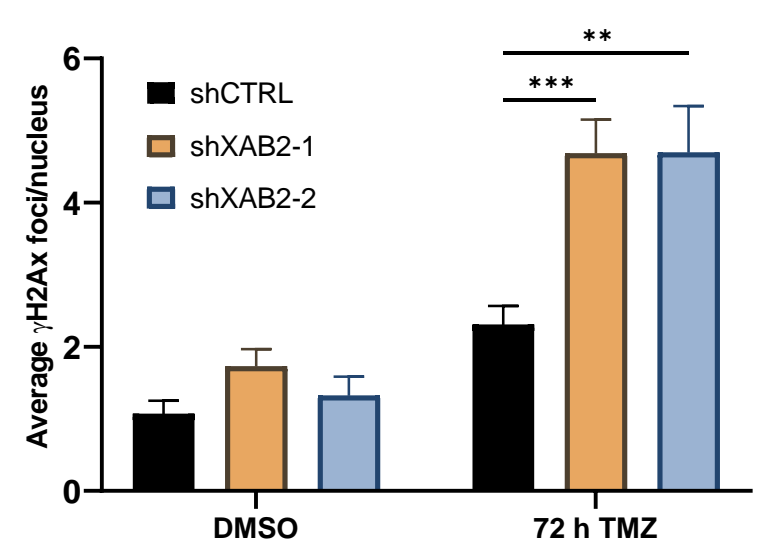

C

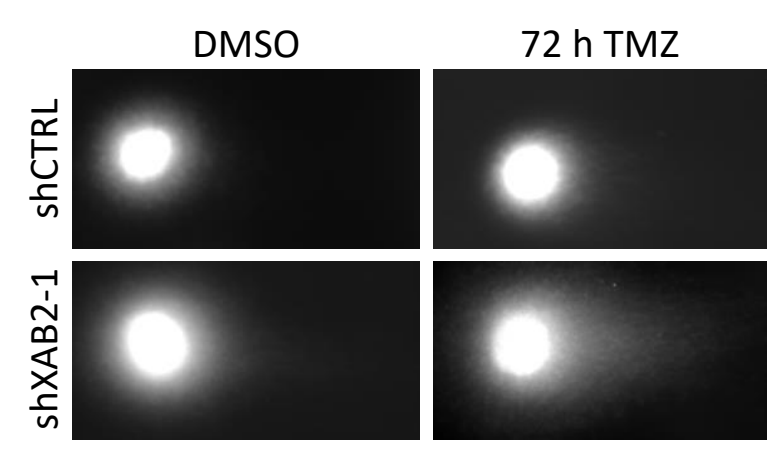

d

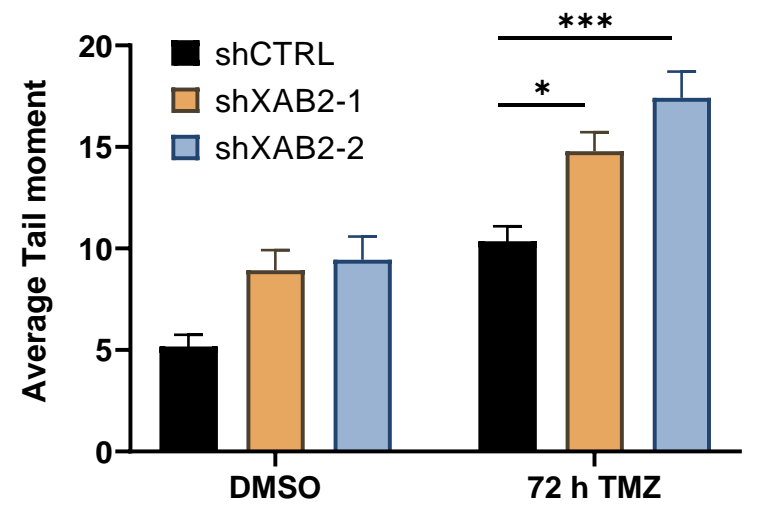

f
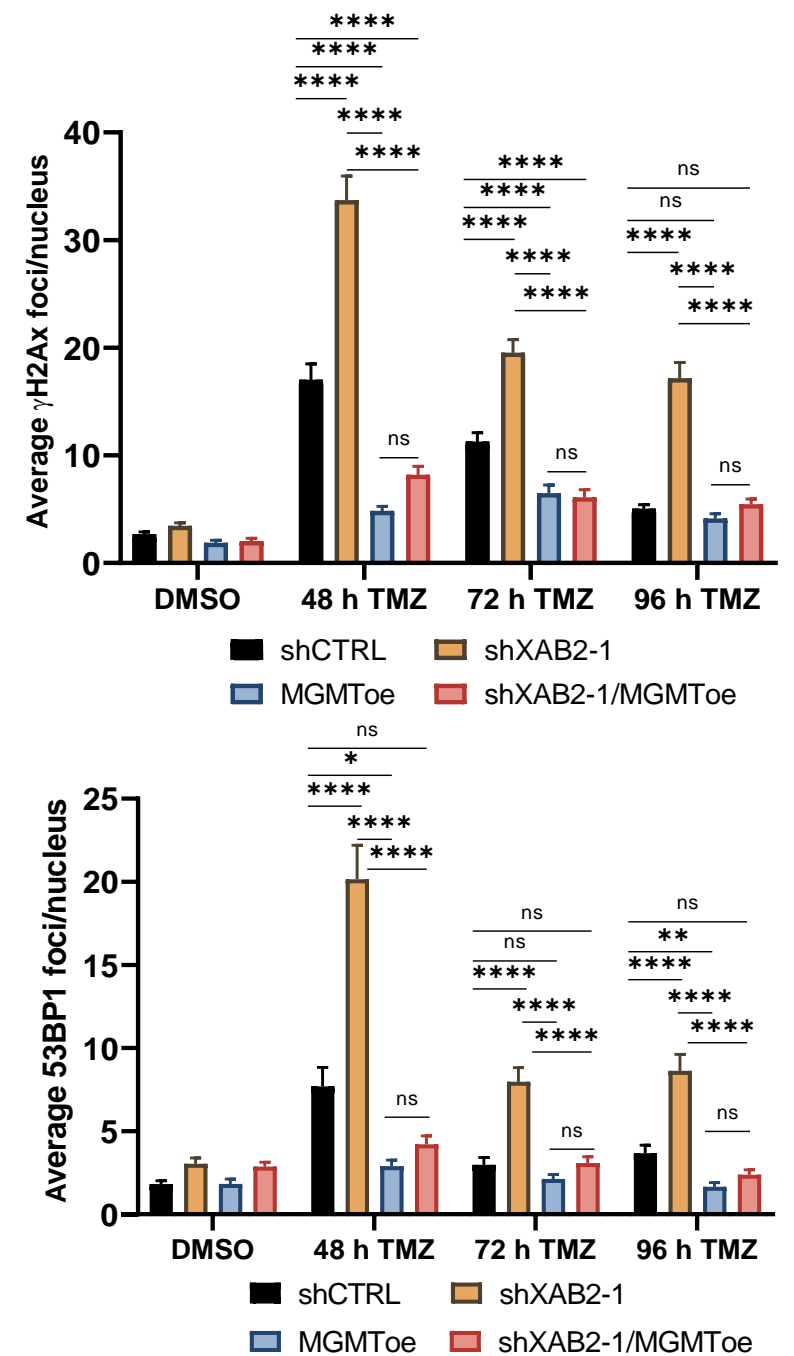

h

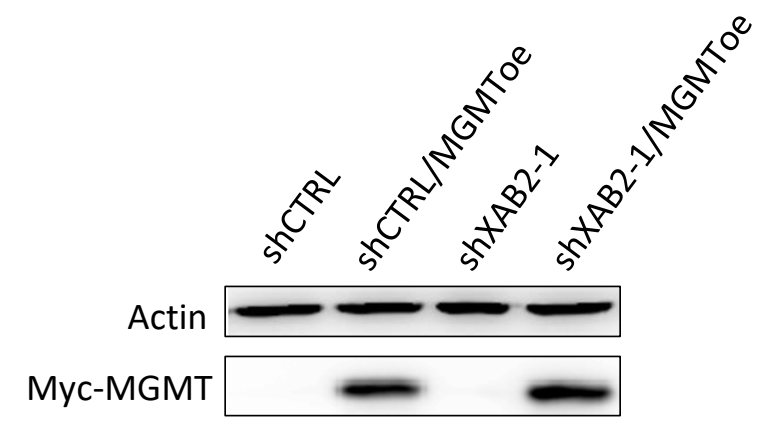


a C $\quad$ Merge + Merge +

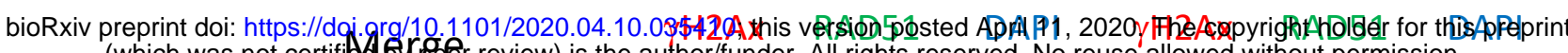
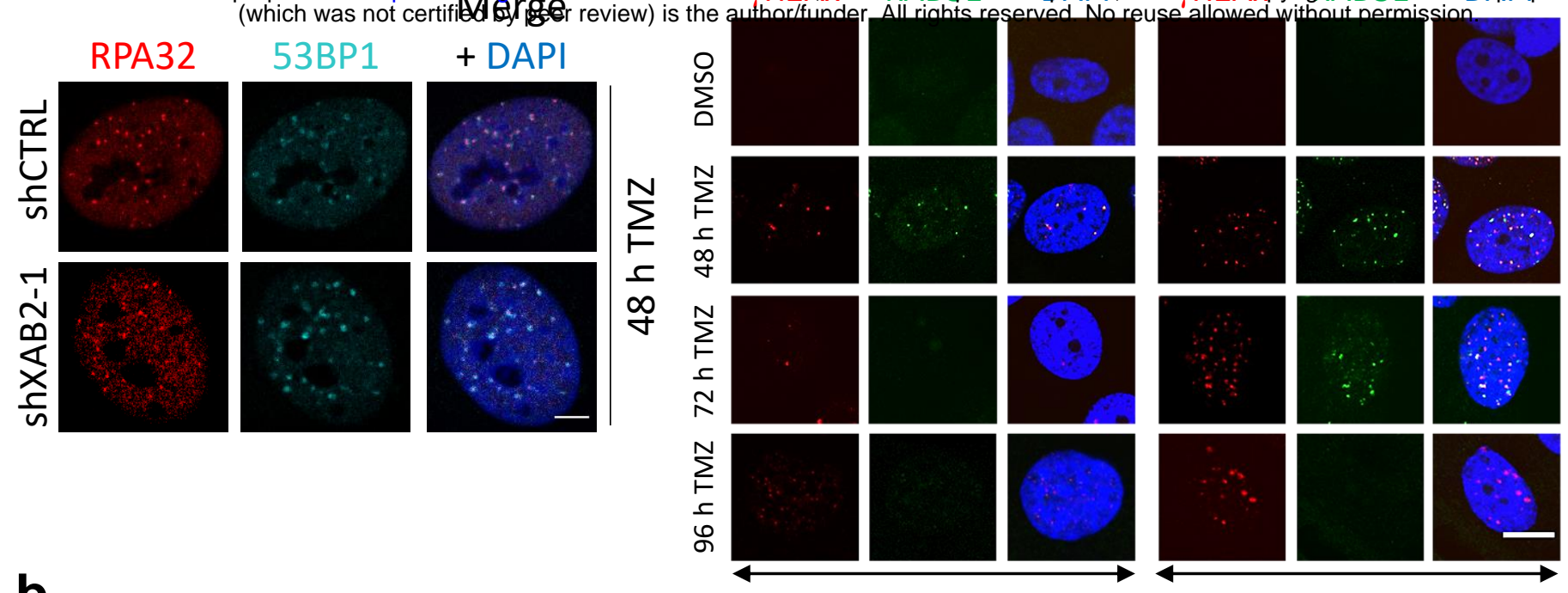

b

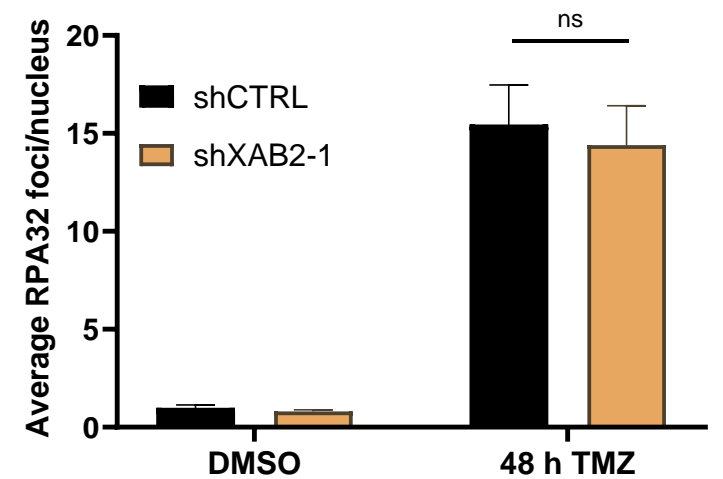

$\mathbf{e}$

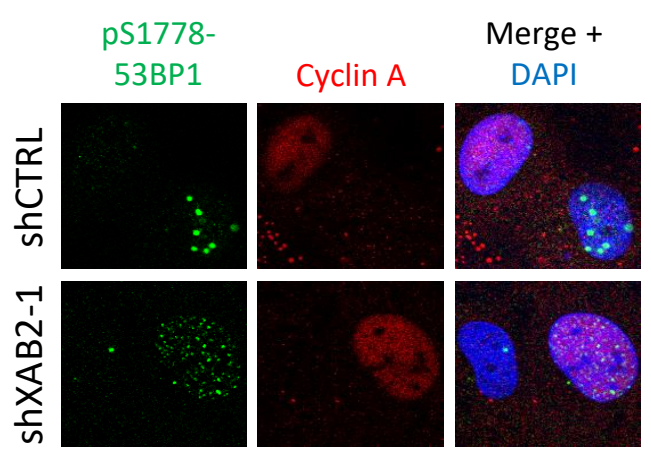

g
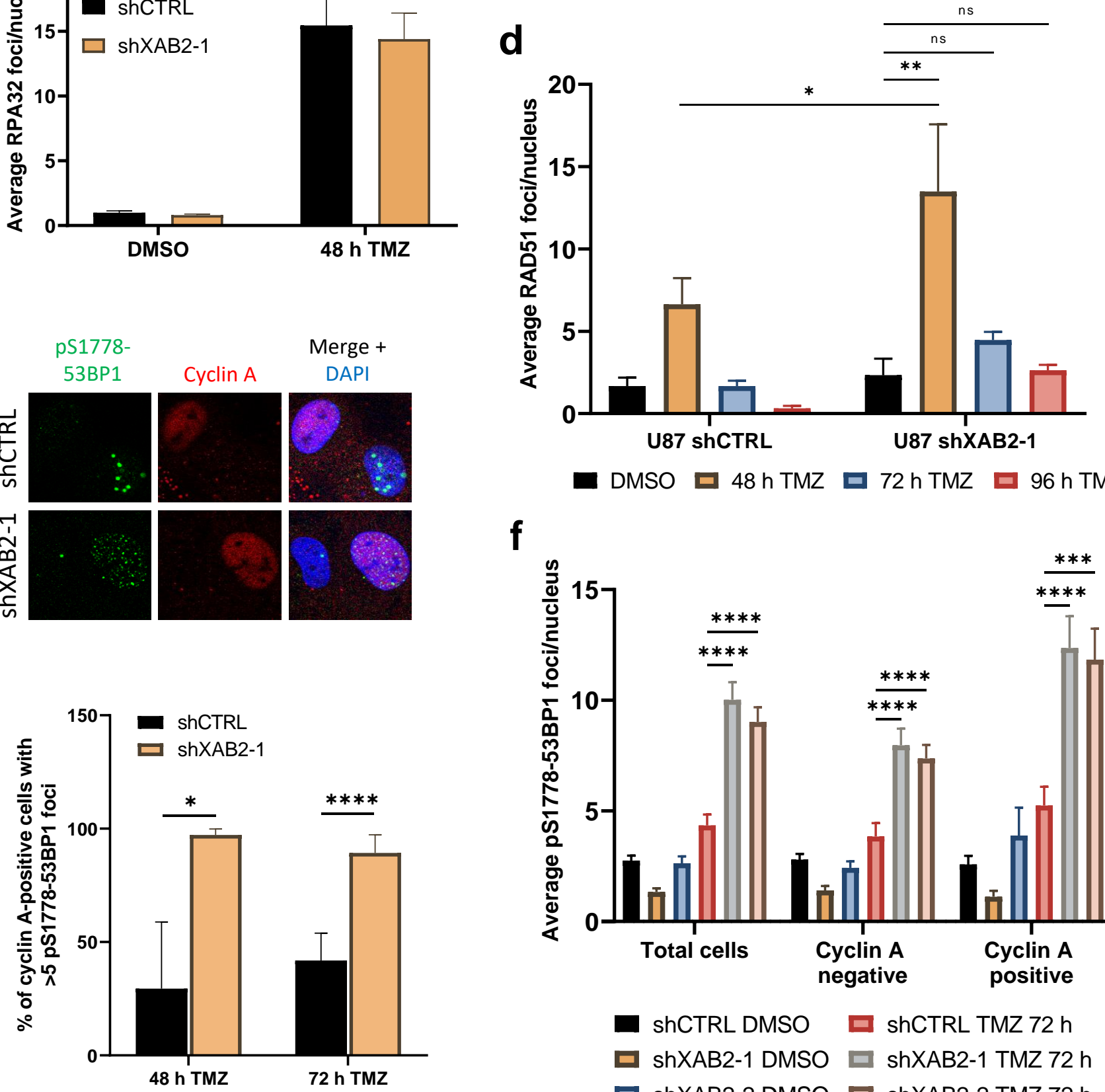

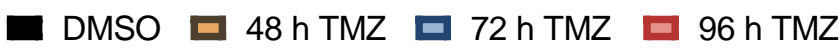

$\mathbf{f}$

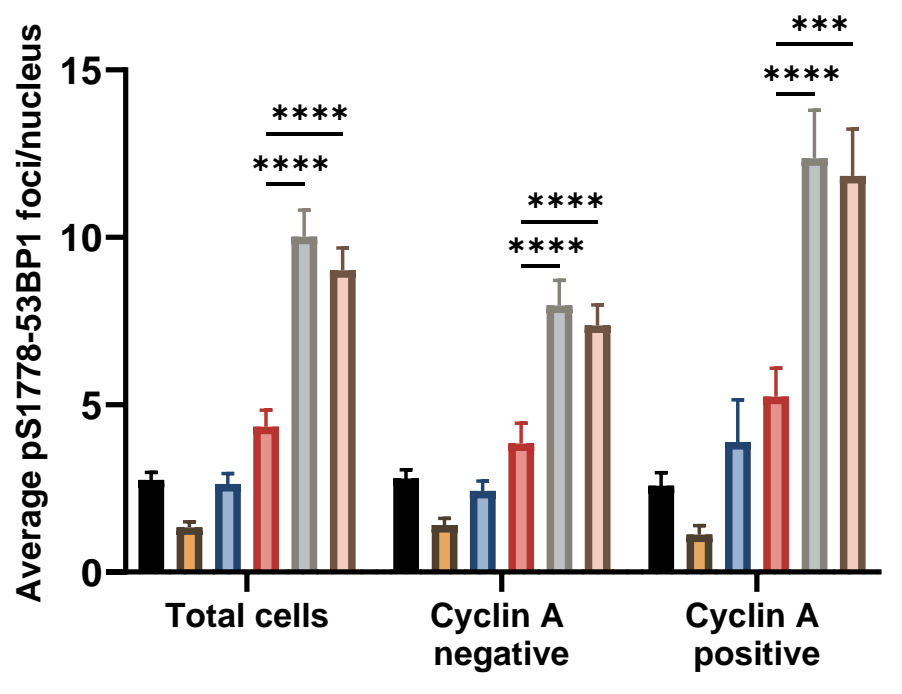

a shCTRL DMSO shCTRL TMZ $72 \mathrm{~h}$

ㅁ shXAB2-1 DMSO shXAB2-1 TMZ $72 \mathrm{~h}$

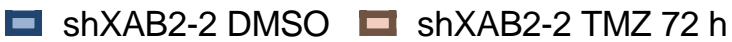




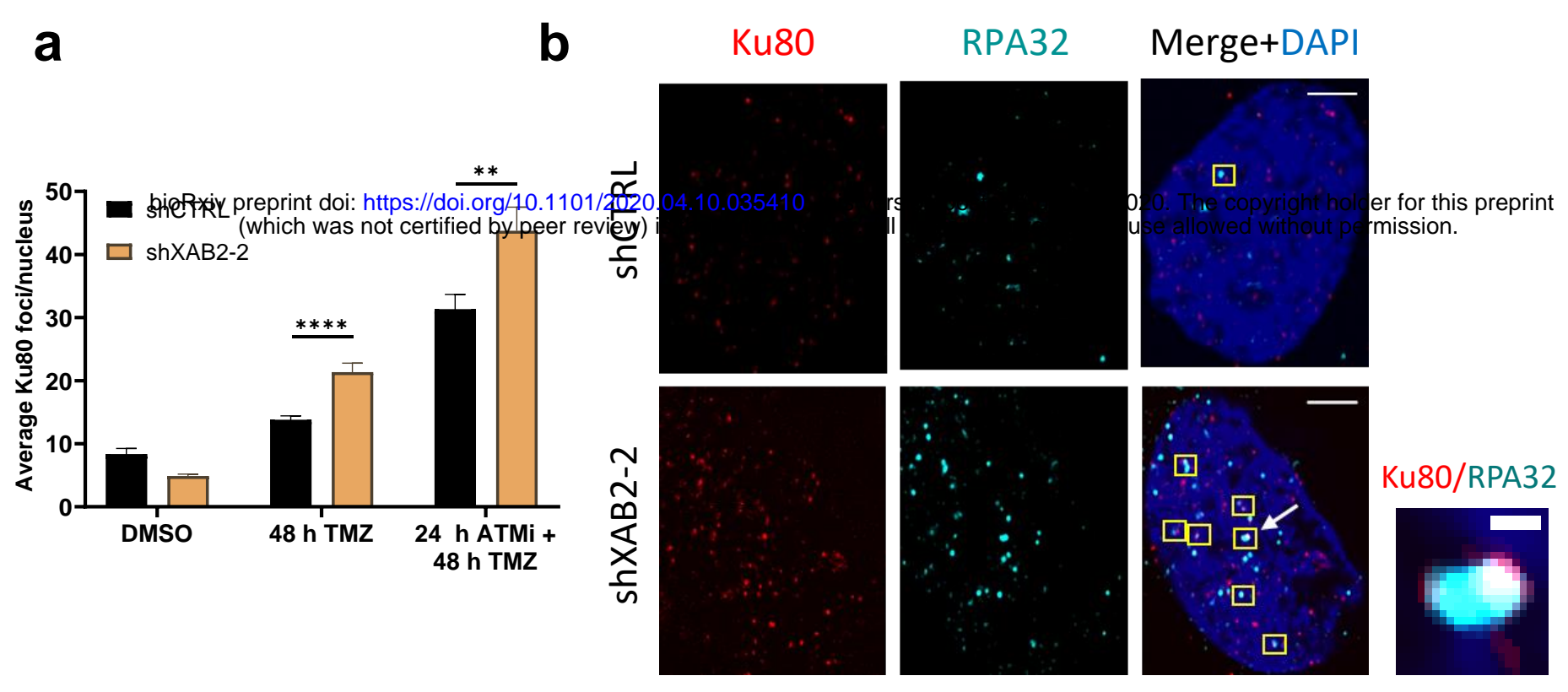

c
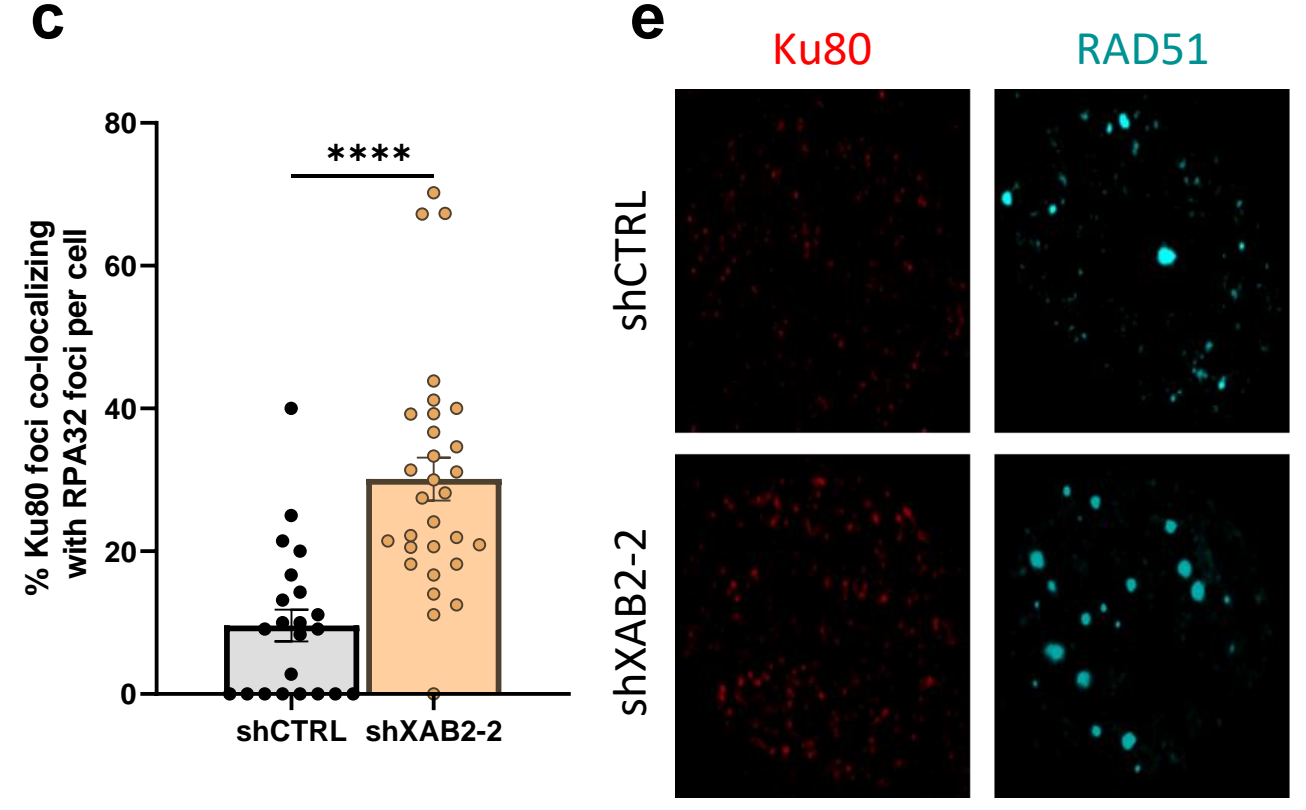

Merge+DAPI
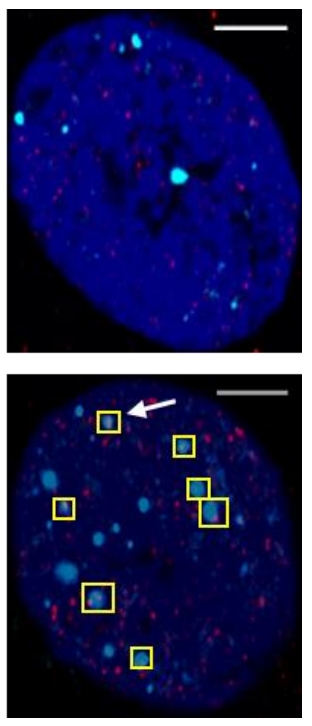

Ku80/RAD51

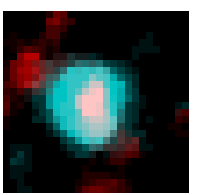

d

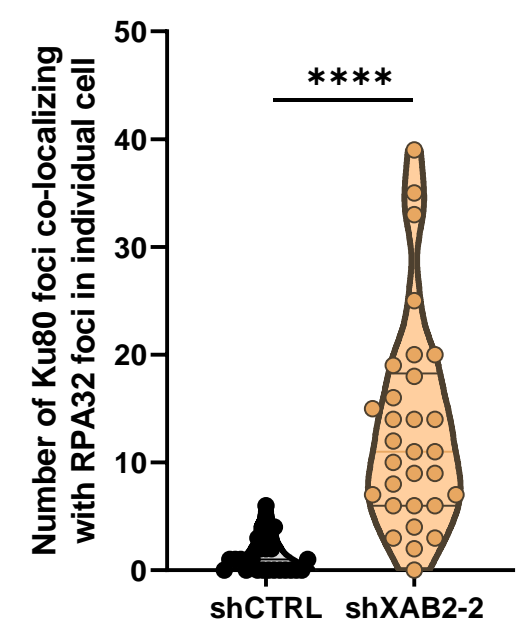

f

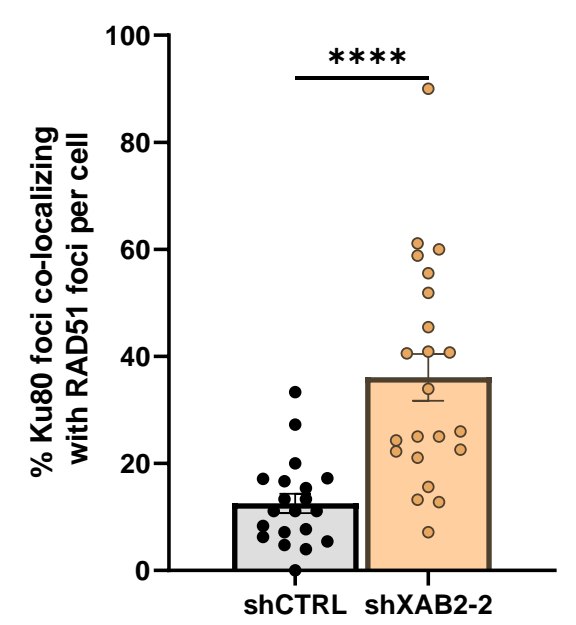

g

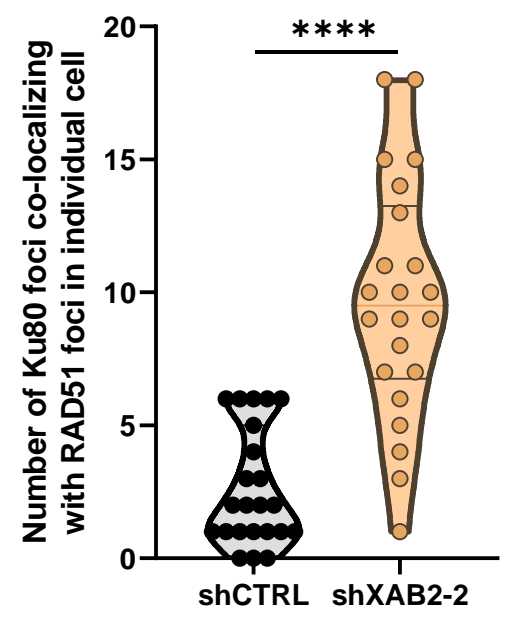




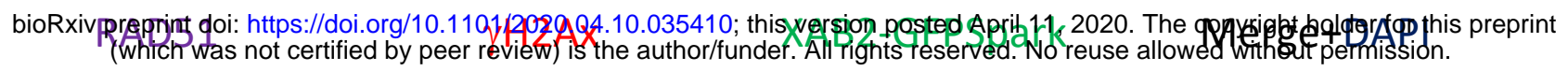

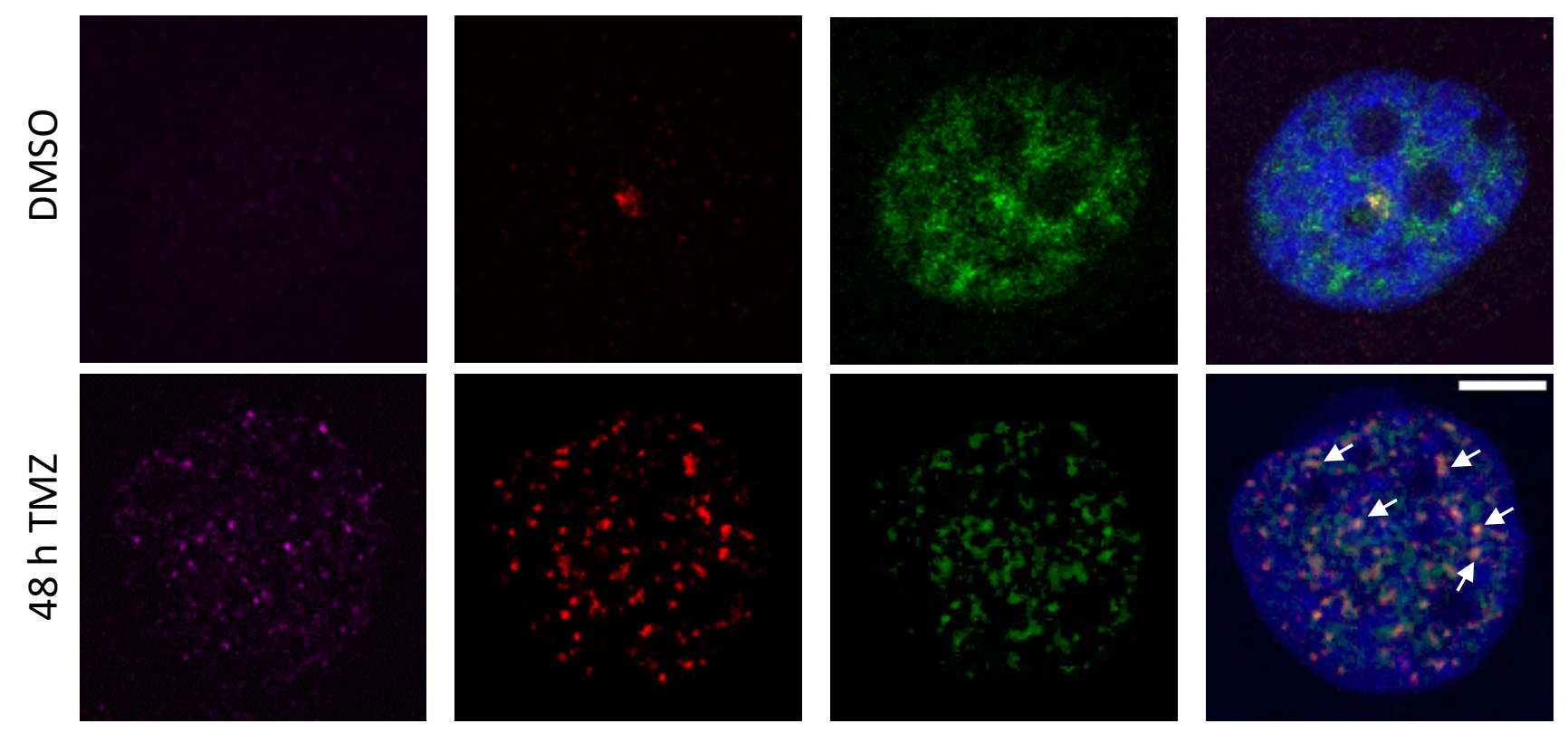


a

b

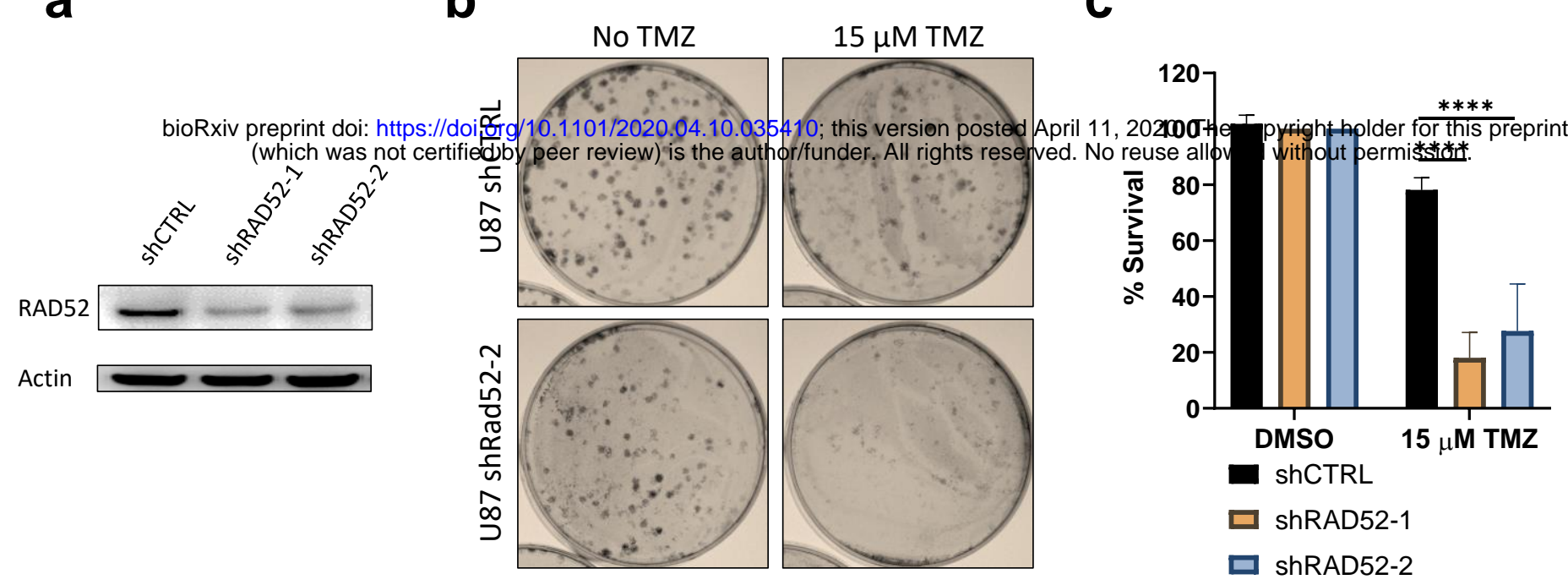

C

d

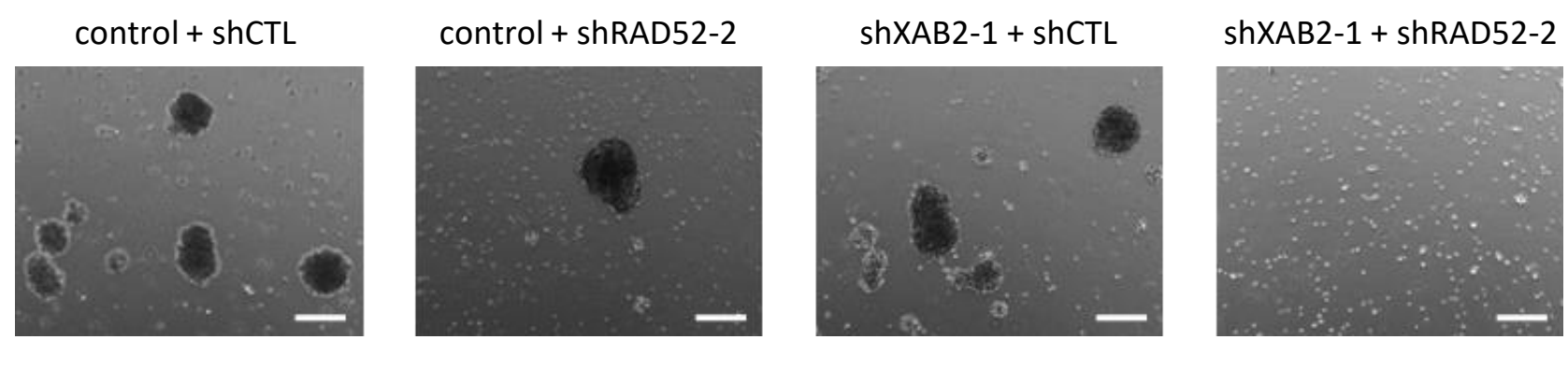

e

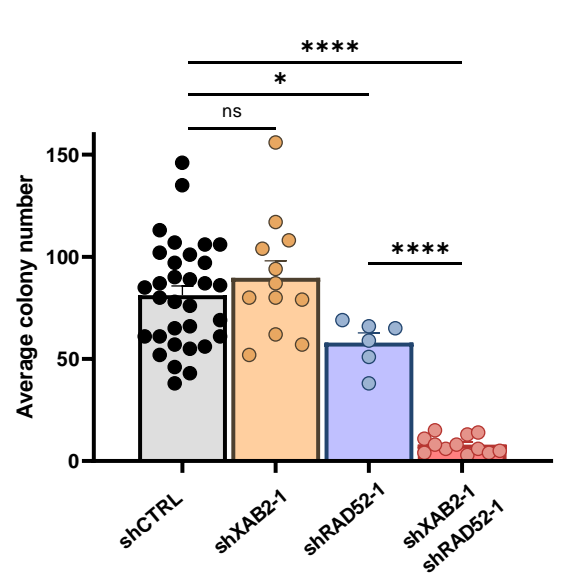

f

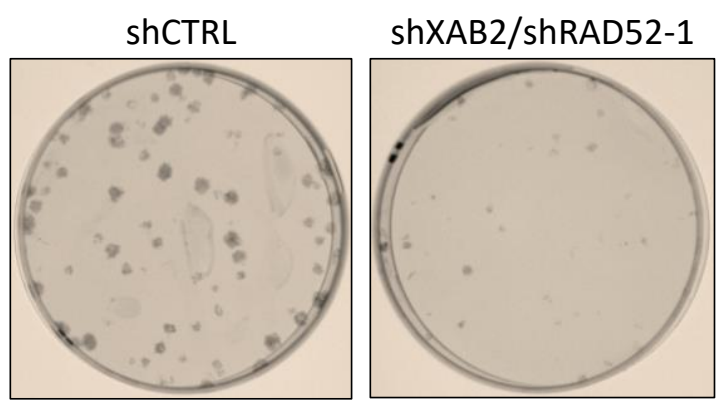

g
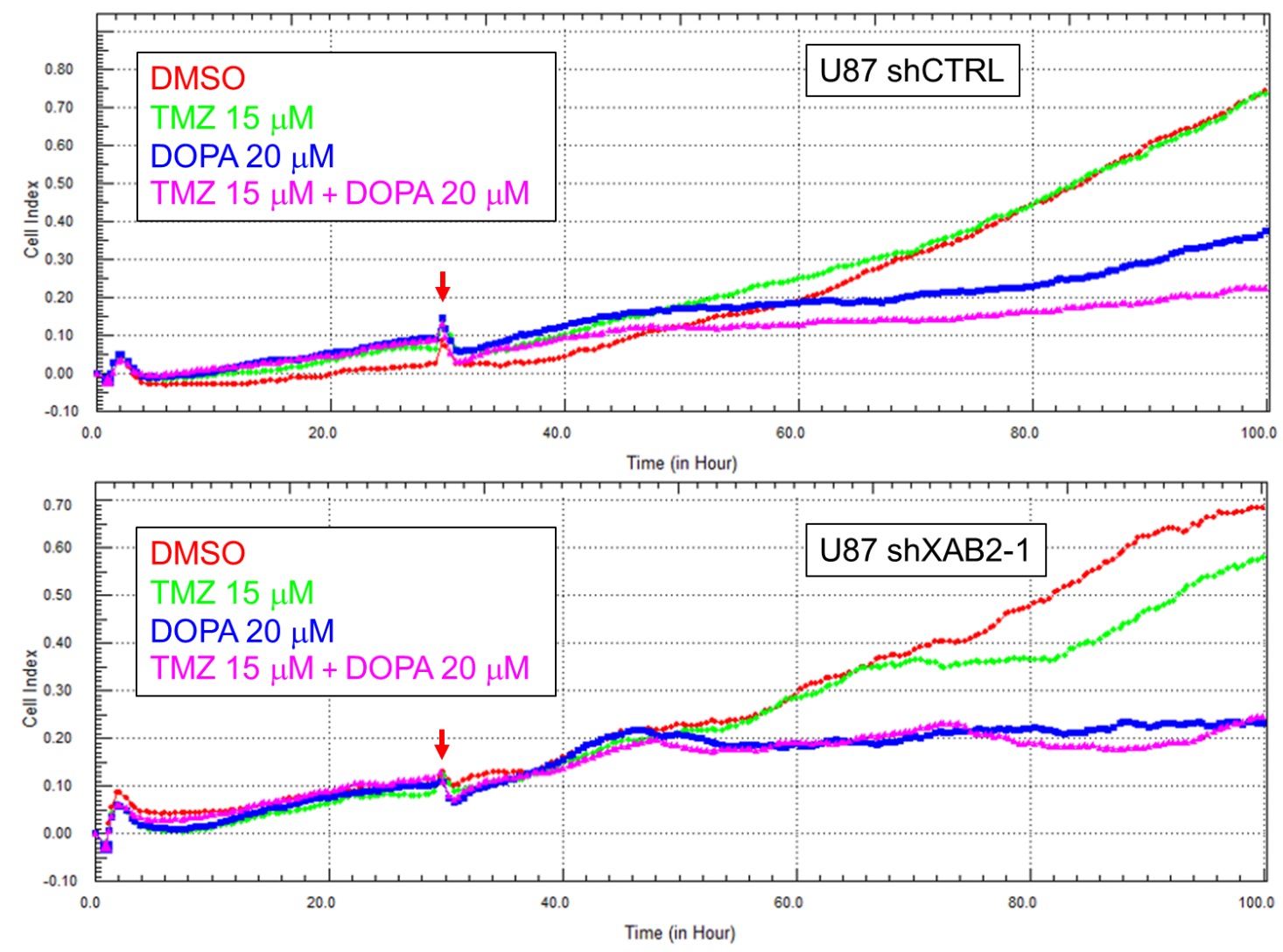
Sharma et al. Fig. 8

\section{Collapsed replication fork}

$\mathrm{Ku}$

seDSB

bioRxiv preprint doi: https://doi.org/10.1101/2020104,10.035410; this version posted_Aprih11, 2020. The copyright holder tor this preprint (which was not certified by peer revieut) is the author/funder. All

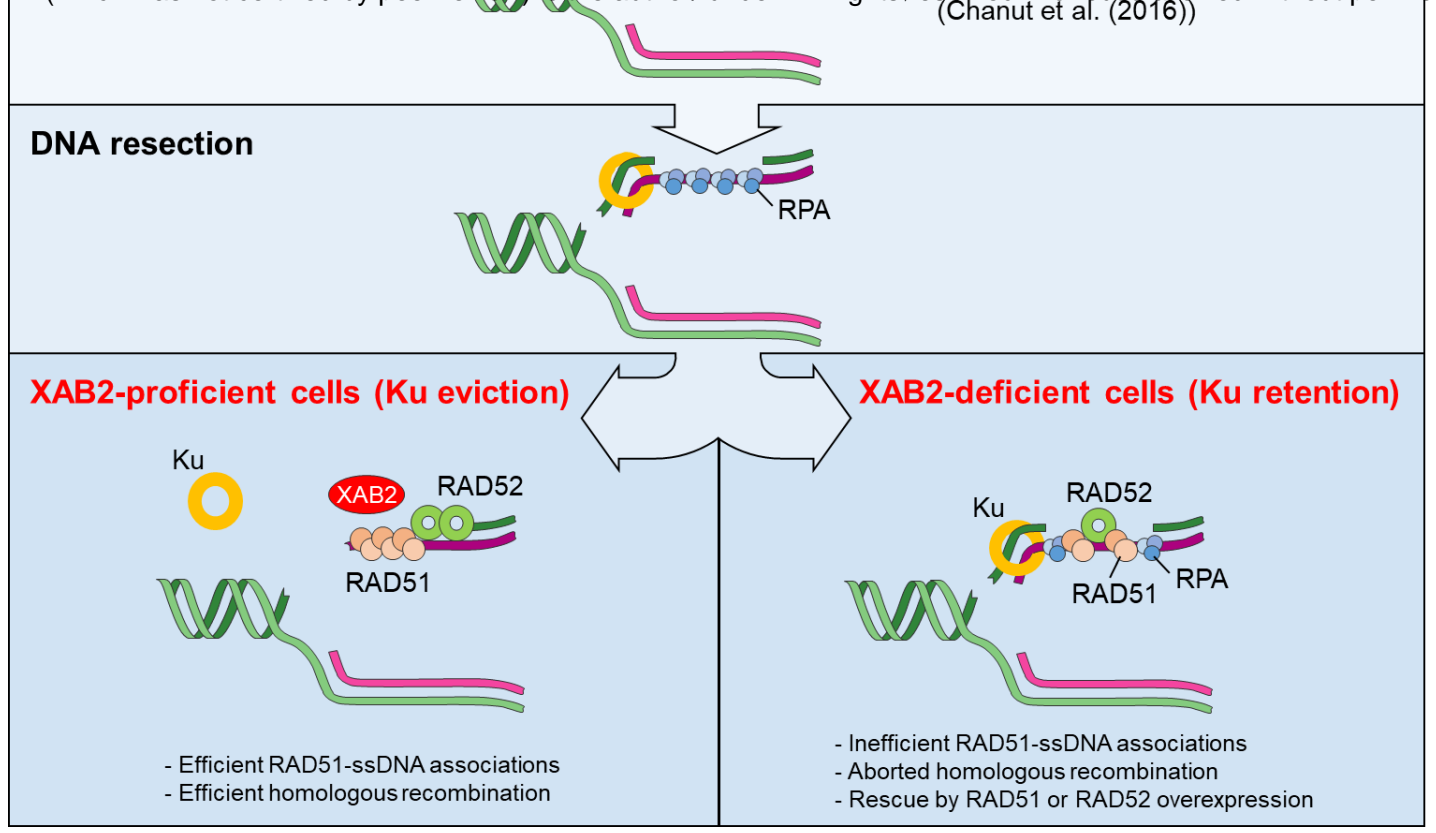

